\title{
Application of Low-Cost Digital Elevation Models to Detect Change in Forest Carbon Sequestration Projects
}

\author{
Final Report \\ August 1, 2005 to July 31, 2007 \\ Principal Investigator: \\ Kenneth Glenn MacDicken, PhD. \\ Winrock International \\ 85 Avenue A, Suite 301 \\ Turners Falls, MA. 01376 \\ (413)863-3087 \\ (413)863-3618 FAX \\ k.macdicken@winrock.org
}

Submitted October 2007

DE-FC26-05NT42437

Winrock International

2101 Riverfront Drive

Little Rock, AR. 72202

Howard Schultz

Aerial Vision Incorporated

108 Wildflower Drive

Amherst, MA. 01002 


\section{Disclaimer}

This report was prepared as an account of work sponsored by an agency of the United States Government. Neither the United States Government for any agency thereof, nor any of their employees, make any warranty, express of implied, or assumes any legal liability or responsibility for the accuracy, completeness, or usefulness of responsibility for the accuracy, completeness, or usefulness of any information, apparatus, product, or process disclosed, or represents that its use would not infringe privately owned rights. Reference herein to any specific commercial product, process, or service by trade name, trademark, manufacturer, or otherwise does not necessarily constitute or imply its endorsement, recommendation, or favoring by the United States. 


\section{Table of Contents}

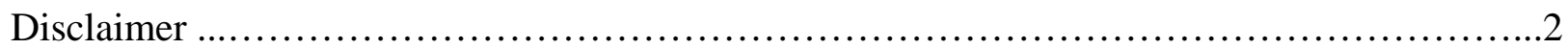

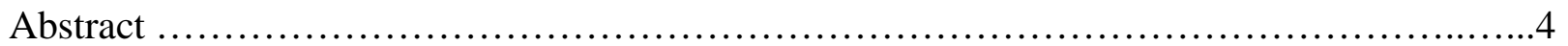

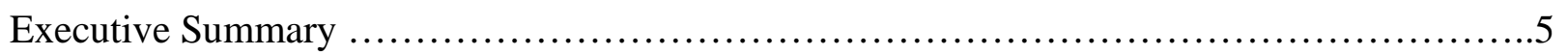

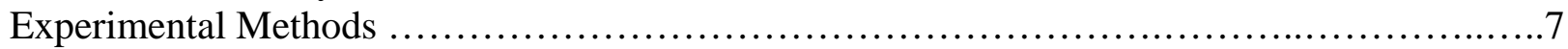

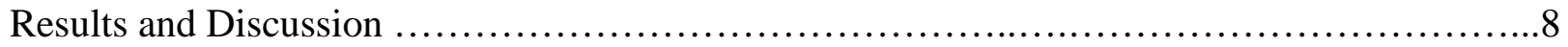

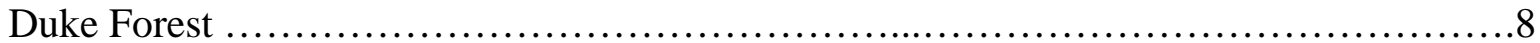

TERREST vs. ERDAS .....................................................8

Analysis of height differences between 2006 and 2002 ERDAS DEMs...................15

Duke Forest ground-based estimates ..............................................

AEP Avondale Wildlife Area, Ohio ............................................18

Analysis of height differences between 2006 and 2002 ERDAS DEMs ..................22

AEP ground plot results .....................................................25

Assessment of automated classification methods for determining canopy objects........32

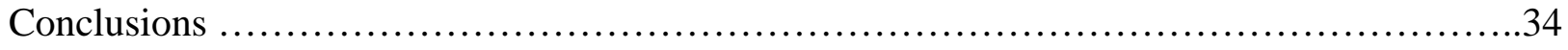

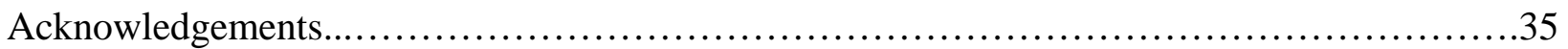

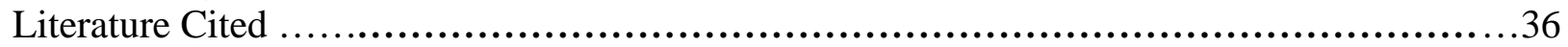




\begin{abstract}
This two-year study evaluated advanced multispectral digital imagery applications for assessment of forest carbon stock change. A series of bench and field studies in North Carolina and Ohio tested aerial assessments of forest change between two time periods using two software packages (ERDAS and TERREST) for Digital Elevation Model (DEM) creation, automated classification software (eCognition) for canopy segmentation and a multiple ranging laser designed to improve quality of elevation data. Results of the DEM software comparison showed that while TERREST has the potential to produce much higher resolution DEM than ERDAS, it is unable to resolve crucial canopy features adequately. Lab tests demonstrated that additional laser data improves image registration and Z-axis DEM quality. Data collected in the field revealed difficult challenges in correctly modeling the location of laser strike and subsequently determining elevations in both software packages. Automated software segmentation of tree canopies provided stem diameter and biomass carbon estimates that were within $3 \%$ of comparable ground based estimates in the Ohio site and produced similar biomass estimates for a limited number of plots in the Duke forest. Tree height change between time periods and canopy segmentation from multispectral imagery allowed calculation of forest carbon stock change at costs that are comparable to those for ground-based methods. This work demonstrates the potential of lower cost imagery systems enhanced with laser data to collect high quality imagery and paired laser data for forestry and environmental applications. Additional research on automated canopy segmentation and multi-temporal image registration is needed to refine these methods for commercial use.
\end{abstract}




\section{EXECUTIVE SUMMARY}

This two-year study evaluated advanced multispectral digital imagery applications for assessment of forest carbon stock change. A series of bench and field studies in North Carolina and Ohio tested aerial assessments of forest change between two time periods using two software packages (ERDAS and TERREST) for Digital Elevation Model (DEM) creation, automated classification software (eCognition) for canopy segmentation and a multiple ranging laser designed to improve quality of elevation data.

Results of the DEM software comparison showed that while TERREST has the potential to produce much higher resolution DEM than ERDAS, it is unable to resolve crucial canopy features adequately. The multiple ranging laser proved more difficult to construct than envisioned, resulting in implementation delays. Lab tests demonstrated that additional laser data improves image registration and Z-axis DEM quality. Data collected in the field revealed challenges in correctly modeling the location of laser strike and subsequently determining elevations in both software packages.

Automated segmentation of tree canopies provided the basis for ally identical to ground based diameter and biomass estimates in the Ohio site and produced similar biomass estimates for a limited number of plots in the Duke forest. Tree height change between time periods and canopy segmentation from multispectral imagery allowed calculation of forest carbon stock change at costs that are comparable to those for ground-based methods.

TERREST is capable of delineating loblolly pine crowns in a manner that cannot be matched by LPS. Unfortunately, TERREST does not translate a triangulated block of images as accurately as LPS. It has a wider range of error in the reproduction of elevation values and spatially distorts the model. Registration problems were minor with the LPS 2006 DEM and easily corrected with a simple affine transform to the 2002 image. Misregistration was more complicated with the TERREST images, which were spatially distorted from both their LPS counterparts and each other.

It may be impractical to attempt to measure the heights of individual trees over time until the microregistration issues are resolved, but stand level changes can be quantified as hypothesized in this project design. Stand level change in carbon stocks detected from DEM measures differed from ground-based measures by $18 \%$ in Duke and only $3 \%$ in the AEP Biosar study area.

We attributed most of the greater difference in the Duke Forest case to poor image quality - in this case due primarily to an undetected engine oil leak that created a film on the lens. When image quality was high, such as in the Ohio imagery, the aerial plot and ground plot results for biomass were very close to one another.

Wide coverage image analysis allows a major advantage over ground-based plots in that the imagery samples represent the true distribution of strata, which are only approximated using ground plots. This was particularly evident in the AEP site where stands recorded as even aged, fully stocked were seen to be less well stocked with uneven population densities. The automated analysis accurately classified these areas 
and provided a useful GIS-based set of results that could not be achieved using standard ground-based methods.

This work demonstrates the potential of lower cost imagery systems enhanced with laser data to collect high quality imagery and paired laser data for forestry and environmental applications. Additional research on automated canopy segmentation and multitemporal image registration is needed to refine these methods for commercial use. 


\section{Experimental methods}

Imagery was collected using Streams 5 software (IO Industries) and their CL160 data capture and synchronization card. Camera system prime components for all data capture were 4 band (RGBIR) MS4100 camera (Duncantech, now GeoSpatial Systems), Attitude and Heading Reference System model AHRS-304 (Watson Industries), Ag132 DGPS (Trimble), and a custom built laser with 5 beams: 1 vertical, $1 @ 5^{\circ}$ left, $1 @ 5^{\circ}$ right, $1 @ 10^{\circ}$ left and $1 @ 10^{\circ}$ right, with each beam firing independently at 240 hertz. The camera, AHRS and laser were permanently affixed in a non-magnetic mount, and then the strike location in image space of each beam was recorded at ranges of $182 \mathrm{~m}$ and $422 \mathrm{~m}$ using an IR reflective material and the IR band of the Duncantech camera. Except the laser, this system was assembled from existing commercial components. The system has a total weight of about 30 kilograms and can be installed in any aircraft for use with a bellyport or mounted externally. The system has no components with US Government export restrictions.

The first phase of the project was focused on creation of more accurate and higher resolution DEMs (Digital Elevation Model) using an accurately measured model of a hardwood forest. The camera system was mounted on a track with known, replicable exposure points. To simulate growth, three blocks of overlapping photographs were taken with the model placed in the same $\mathrm{X}, \mathrm{Y}$ position on the table but raised in the second and third set by $11.9 \mathrm{~mm}$ and $23.8 \mathrm{~mm}$ respectively. At each height increment, the visible laser was used to measure the surface elevations in the same $10 \mathrm{~cm}$ grid. Each set of imagery was compared to measure the system's ability to measure change using Erdas Imagine's LPS (Leica Photogrammetry Suite). These same sets of imagery were then processed using the University of Massachusetts' Terrest software at a higher resolution.

In the second phase of this project, the same methods, software, and hardware were then applied to data collection flights over the FACE (Free Air CO2 Enrichment) site at the Duke University Forest in Chapel Hill, NC and selected sites owned by AEP (American Electric Power) near Avondale, $\mathrm{OH}$. An aircraft oil leak degraded the imagery, but sufficient data was collected for analysis.

Aerial imagery was collected at an average airspeed of $193 \mathrm{~km} / \mathrm{hr}$ and an altitude of 262 $\mathrm{m}$ to yield $10 \mathrm{~cm}$ pixel-1 imagery over the Duke Forest and an altitude of $381 \mathrm{~m}$ over the AEP lands for $15 \mathrm{~cm}$ pixel-1 in Ohio. In both instances images were collected at $2 \mathrm{~Hz}$, while the laser and AHRS recorded at their maximum rates of $240 \mathrm{~Hz}$ and $70 \mathrm{~Hz}$, respectively. A Cessna 210 aircraft with bellyport was used at both locations. All data were recorded to external high speed drives in Streams 5 format and extracted with time stamps appended post flight to standard 4 band tiffs and text files. The laser data was found to be of reasonable quality, although a significant number of returns were not detected.

With each imagery set, block files were made in LPS, laser points were placed on the image as control points and automatic tie points were created. Each block was 
triangulated to an overall RMSE (Root Mean Square Error) of 1 or less. Once this was achieved, DEMs were created at the smallest scale possible, generally $45 \mathrm{~cm}$ of Ohio imagery and $30 \mathrm{~cm}$ for Duke imagery using a $3 \times 3$ window for DEM creation, rather than the standard 10x10 window. Using these DEMs as a base, the imagery was then orthomosaicked.

The Terrest software was then run using the same images and the LPS triangulation report. The finest resolution was selected, where DEM resolution was equal to pixel resolution. Field checks were performed at each site to measure GPS heights at the laser strike locations for comparison to interpolated heights and Terrest derived values.

Ground data were collected from two sources: FACE experimental data from the Duke Forest was made available by FACE project administrators and field data for the Ohio sites was collected by Mr. Gary Kaster with support from American Electric Power. The Duke Forest data provided a multi-temporal dataset that was well delineated by the FACE CO2 emission towers, while the Ohio data provided commercial-scale carbon inventory information as well as data for allometric equations used in the calculation of above-ground biomass carbon.

\section{Results and Discussion}

Prior to flights in North Carolina and Ohio we implemented a set of bench test experiments utilizing the Winrock calibration table to systematically evaluate comparisons between a series of Digital Elevation Models (DEMs) of a topographic model at simulated growth intervals. Two different types of surface modeling programs, ERDAS LPS and TERREST were compared for their relative error in reproducing the measured surface of the topographic model and their possible application to forest canopy delineation. A paired $t$ test showed the mean differences to be highly significant $(p=0.001)$ demonstrating that this initial TERREST run produced measured - DEM estimates that were on average were more than two times those produced by ERDAS.

TERREST uses a different method of generating a DEM from an ERDAS block file, calculating the elevation of each pixel in the overlapping photographs to produce a surface model with the same resolution as the original imagery. This increase in modeling detail approaches the ideal case in which the laser grid point sample size and the DEM had the same resolution, and the program would be able to model the hole in the physical model. If this can be achieved, it should reduce the Delta values between the DEM and the measured elevations, but the process is still experimental. The initial DEM from ERDAS blocks of the topographic model supplied to Dr. Schultz have higher resolutions than the ERDAS DEM, but significantly poorer Delta values. The value of these bench test results is that they clarified software resolution and accuracy differences that may have been confounded with georeferencing and vegetation related factors. 


\section{Duke Forest}

\section{TERREST vS ERDAS}

ERDAS LPS uses a more traditional photogrammetric approach, calculating image parallax from 7-by-7 pixel blocks between epipolar image pairs and using them to populate elevation points in a grid. This approach is robust and accurate, but decimates the pixel size of the product DEM in relationship to the resolution of the original imagery, though the most recent version of LPS, ERDAS 9, is a distinct improvement over earlier software. The $15 \mathrm{~cm}$ per pixel imagery of the 2002 photography was originally processed to a 1-meter per pixel DEM with ERDAS 8.6, but ERDAS 9 reduced the minimum pixel block for DEM production to 3-by-3, producing $50 \mathrm{~cm}$ DEMs from the 15 $\mathrm{cm}$ imagery.

The TERREST program, written by Dr. Howard Schultz of the Computer Science program at the University of Massachusetts, takes a more radical and still experimental approach, determining the elevations of individual pixels at the resolution of the original imagery by calculating their parallax on all images that overlap that point and between the multispectral bands. Dr. Schultz has produced a working version of his program for the Windows platform and Winrock used it to produce DEMs for this study. The program should generate accurate DEMs from $15 \mathrm{~cm}$ imagery at $15 \mathrm{~cm}$ per pixel resolution, but we had problems producing image files at that level.

Neither LPS nor Terrest do a good job of reproducing the auto-tie-point surface of a 2006 block file over the FACE site (Table 1). This is partly a function of the higher RMSE values and a poorer spread of auto-tie-points that were assigned elevation values in the final block. The fact that the vertical RMSE of the control point in this block is higher indicates that a significant amount of $Z$ value tie-point error is being distributed to the control points in order to form the block.

Table 1. Comparison of $\Delta$ values for 2006 FACE-subsection block file

$\begin{array}{ll}\text { Mean } \Delta \text { for } 50 \mathrm{~cm} \text { LPS model } 2006 & 3.54 \\ \text { Standard Deviation } & 3.50 \\ \text { Coefficient Variation } & 101 \% \\ \text { Range of Error } & -18.0 \text { to } 7.9 \\ \text { Mean } \Delta \text { for } 15 \mathrm{~cm} \text { TERREST model } 2006 & 2.97 \\ \text { Standard Deviation } & 2.06 \\ \text { Coefficient Variation } & 69 \% \\ \mathrm{~N} & 578\end{array}$

Absolute errors between each model and its assigned elevation values from the triangulation report were calculated by sampling each surface at the geographic locations of those tie-points. Some automatic tie-points have higher error than the RMSE value of the block and were discarded in the DEM production. However, if 
TERREST accurately reproduced the elevation model of the triangulation, it would have a more accurate correspondence to the assigned values of the block. Instead, the mean $\Delta Z$ and standard deviation for the points in the $50 \mathrm{~cm}$ LPS model are lower than the 15 $\mathrm{cm}$ TERREST model, indicating that it is a better translation of the triangulation in spite of the higher resolution of the TERREST model. The TERREST program also distorts the spatial properties of the block and this may contribute to the higher error.

The higher error rate and spatial distortion seen in the Terrest software demonstrate that it is less accurate in producing the Duke Forest surface, just as it was less able to accurately reproduce the surface in the calibration table tests.

If the 2006 Time 2 DEM is successfully registered to the elevation model of the 2002 Time $1 \mathrm{DEM}$, common points on open ground should have approximately the same elevation values. The first step in a difference analysis between the two was to verify that similarity. This was made more difficult by the number of artifacts in the 2006 model, but five identifiable points were identified with values within $+/-60 \mathrm{~cm}$ of each other.

With this open area correspondence between the two DEMs verified, a difference file was generated over a portion of the stand canopy and the mean height change calculated. That value of 2-meters growth over the four-year period is consistent with Duke's measurements and estimates for tree growth in the stand. The range of difference values from -11 to $16 \mathrm{~m}$ indicates that individual tree height change is not reliably detected using this approach. 


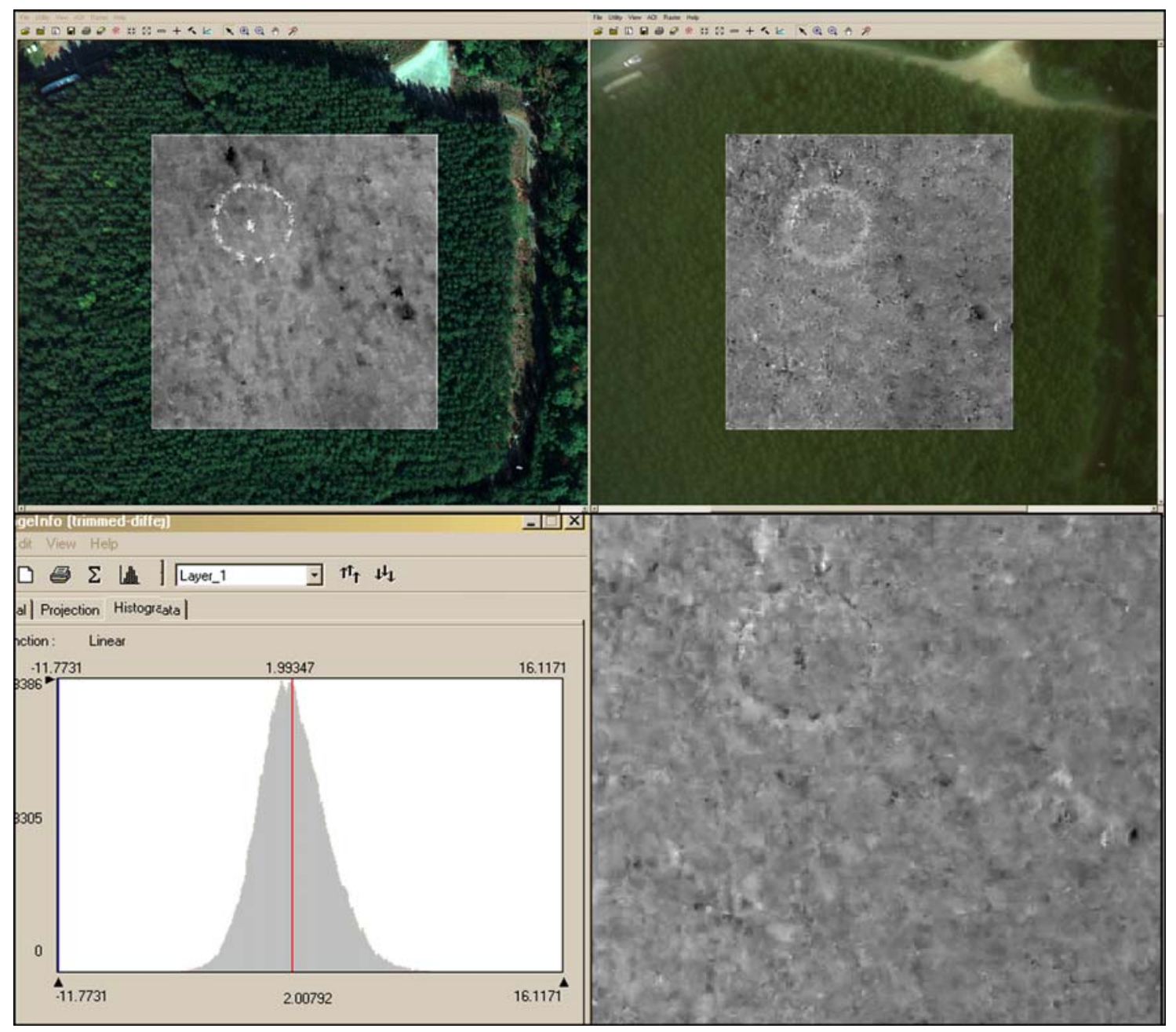

Figure 1. The 2002 (left) and 2006 (right) $50 \mathrm{~cm}$ ERDAS DEMs trimmed to a section of the loblolly pine stand. A difference file between the 2002 model and 2006 model (lower right) shows a mean difference of two meters, consistent with Duke's on-site measurements.

If this model is trimmed to only positive values, the mean difference increases to 2.5 meters (Table 2), which compares with $m$ as measured from the ground. The $\mathrm{CO} 2$ emission tubes on some of the FACE towers were raised for some rings between the two time periods, so the 2006 DEM also picks up PVC tube changes as "growth", which we estimate accounts for < approximately $10 \%$ of the total change between these two periods.

Most artifacts are symmetrical, with spikes extending both up and down. Removing the negatives values in these cases would result in a higher mean value for the difference file that is still a distortion of the non-artifact values.

Because of their symmetrical nature, those artifacts that manifest themselves as up and down spikes in the DEM surface can be reduced by running a convolution filter over the DEM and averaging them to each other. If the original difference file is treated with a 
$5 \times 5$ low pass filter and then truncated to positive values (Table 2) the mean difference value drops to 2.4 meters with a slightly better coefficient of variation.

Table 2. Original and positive only values for the difference file between 2002 and 2006 LPS DEMs over the FACE site loblolly pine stand.

$\begin{array}{ll}\text { Mean Value for } 50 \mathrm{~cm} \text { LPS difference file } & 2.06 \\ \text { Standard Deviation } & 1.61 \\ \text { Coefficient Variation } & 78 \% \\ \text { Range of Difference } & -11.0 \text { to } 16 \\ \text { Mean of Positive Values for } 50 \mathrm{~cm} \text { LPS } & \\ \text { difference file } & 2.54 \\ \text { Standard Deviation } & 1.46 \\ \text { Coefficient Variation } & 58 \% \\ \text { Range of Difference } & 0 \text { to } 11 \\ \text { Mean of Positive Values with } 5 \times 5 \text { low pass } & \\ \text { convolution } & 2.36 \\ \text { Standard Deviation } & 1.2 \\ \text { Coefficient of Variation } & 51 \% \\ \text { Range of Difference } & 0 \text { to } 9\end{array}$

A measure of stand height change can be obtained by measuring the difference in height of specific loblolly crowns that remain in the stand between the two over-flights. If the two layers are accurately registered to each other, this test can also indicate the extent to which the two surfaces actually correspond. Individual elevation points were identified on top of trees within the six-meter range of tree heights in the $2002 \mathrm{DEM}$ and then subtracted from their corresponding points on the 2006 DEM. If growth was consistent between pines, and both DEMs were accurately measuring the same crowns at different stages of their growth, one would expect that consistent growth to be reflected by a similar difference in height between the originally shorter and higher trees.

Table 3. Positive changes in the crown height measurements of sample loblolly pines between the 2002 and 2006 DEMs

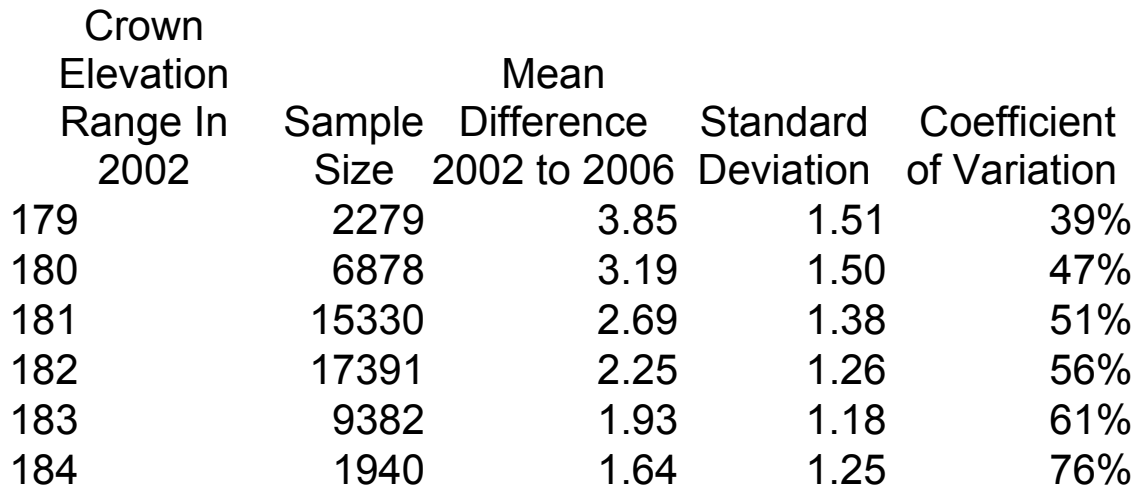


The 2006 FACE site data presented the challenge of high RMSE values of the block (Table 3) that came from an inadequate spread of auto-tie points even when ground control points from the 2002 mosaic and DEM were used to register the block. This problem was addressed by using the accurately georeferenced mosaic of the 2006 images as a reference and manually placing all the available 5-beam returns on their adjacent frames as horizontal control points at their actual pixel positions on the rectified mosaic instead of the geographic positions calculated as trigonometric offsets from the original flight positions. This resulted in a set of ground coordinates for the laser returns that reflected the position and orientation of the camera based on the original ground calibration of the 5-beam laser to specific pixel coordinates on each frame.

GPS points were recorded at the location of 12 laser strike locations in the Duke Forest, and were found to have $Z$ values with a mean difference of $-4.44 \mathrm{~m}$ of the 2006 Terrest DEM height values. As most of these locations were forested, this would indicate that the Terrest DEM values were systematically too low. Further comparison of these points with the anticipated $Z$ values from the laser returns indicates that the mean laser strike elevation was $9.8 \mathrm{~m}$ higher than the mean GPS point elevation. This seems to indicate that the lasers were penetrating a small distance into the canopy, but not reaching the ground, which is consistent with well-stocked loblolly stands. There was only a single instance where the reported GPS elevation was equal or greater than the reported laser strike elevation.

The first step comparing Time 1 and Time 2 data was to construct new block files and DEMs of both the original $200250 \mathrm{~cm}$ and $15 \mathrm{~cm}$ imagery using the increased accuracy and resolution of ERDAS LPS 9. A two-meter resolution DEM and ortho-mosaic were produced from the $50 \mathrm{~cm}$ coverage to provide a registration base for the bulk of the 2006 coverage. A $50 \mathrm{~cm}$ resolution DEM and ortho-mosaic were produced from the 15 $\mathrm{cm}$ coverage of the FACE research stand of loblolly pine and used to register a portion of the 2006 photography that covered the same area.

The original 2002 canopy model appeared to be a good fit with Duke Forest field measurements, and that data was considered to be an accurate representation of the terrain and canopy in 2002 and was utilized as a source of 3D control points in compiling the 2006 imagery. 3D control points for the 2006 block files were drawn directly from the ortho-mosaics and DEMs of the 2002 coverage, selecting both ground points of known position and elevation that remained unchanged and discernable features on open ground. Where necessary to improve the block, horizontal control points were selected from distinctive features in the canopy.

Returns over the one portion of the Blackwood Division that had a field of open ground with known elevations were erratic, but consistent with the Delta error between the lasers and the presumed accurate DEM from the $200250 \mathrm{~cm}$ coverage (where differences should be limited to the amount of possible growth after editing the points for removed trees). 


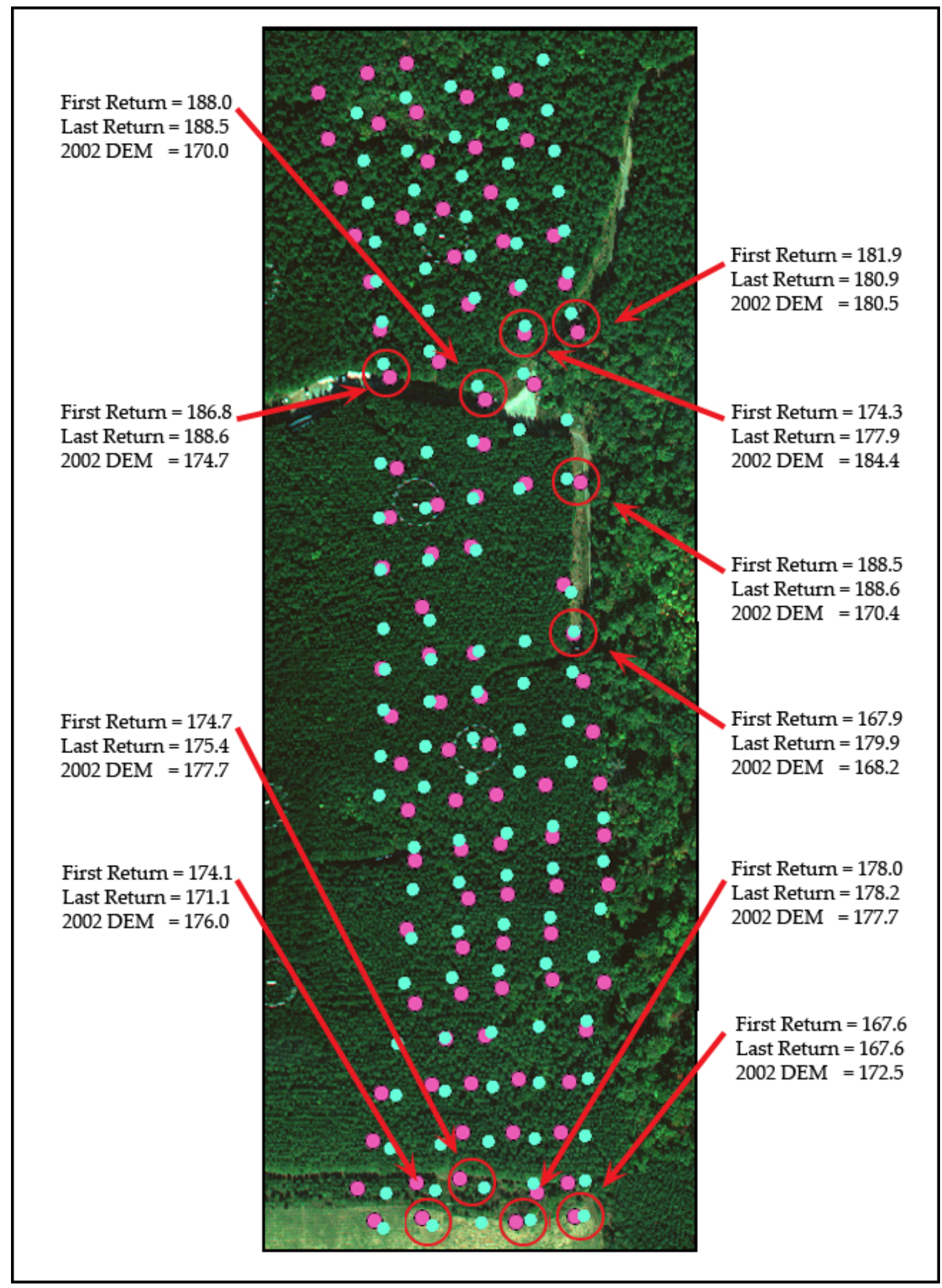

Figure 2. Laser positions calculated from flight positions (cyan) compared to the manually determined positions from the old pixel locations of each laser on the rectified base (purple). 
Delta of 5-band laser over Duke Forest Site

$\begin{array}{ll}\text { Average Delta } & 11.10332678 \\ \text { Standard DEV } & 22.70263045 \\ \text { Range of Delta } & -35 \text { to } 106\end{array}$

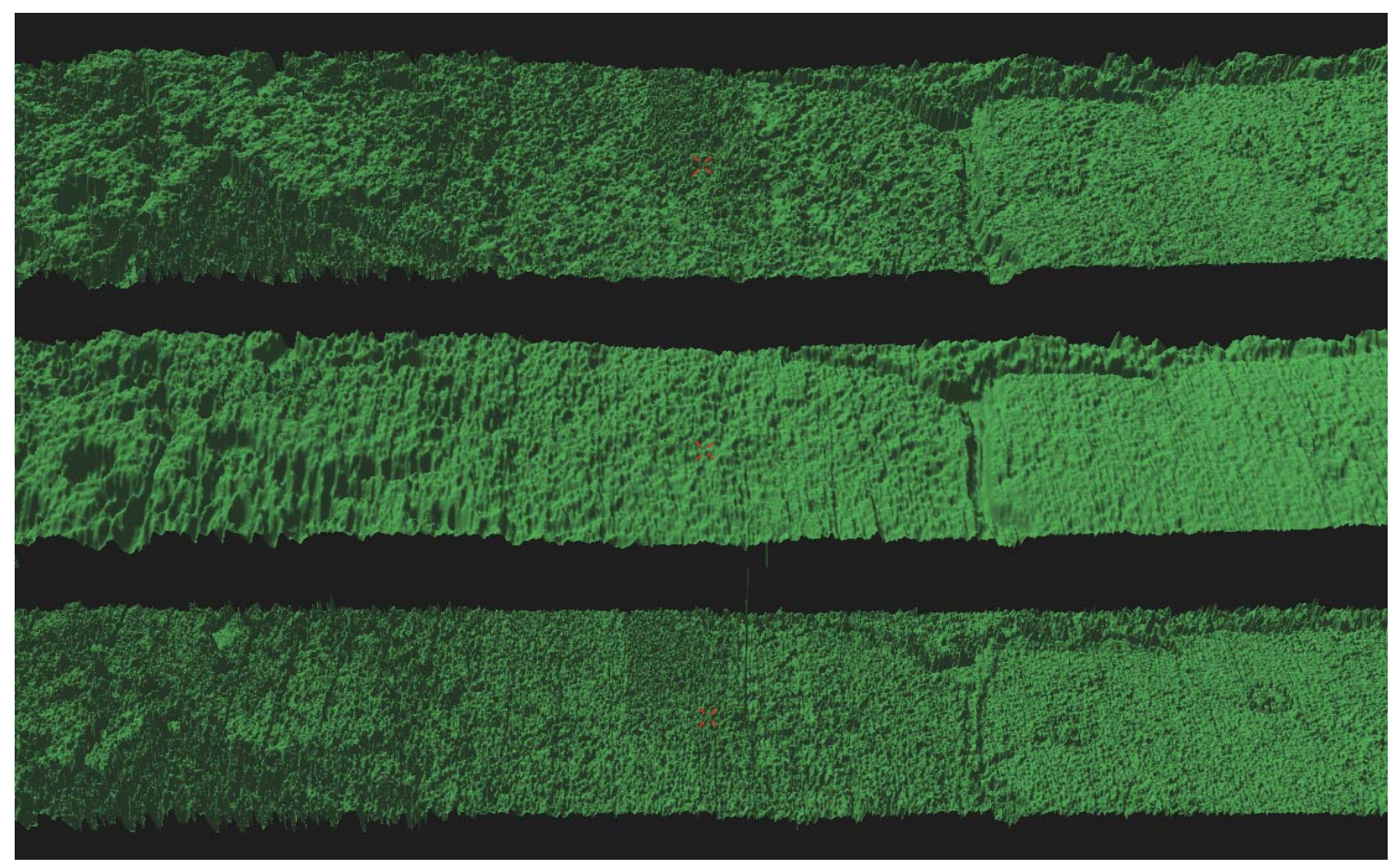

Figure $3.50 \mathrm{~cm}$-per-pixel ERDAS DEM from the subsection of the $200215 \mathrm{~cm}$ line-2 coverage (top) compared to 1-meter-per-pixel TERREST DEM (middle) through a difference file (bottom).

Both modeling programs use the bundle-adjusted triangulation block created by ERDAS to generate a surface of the terrain and ERDAS assigns elevation values to the automatic tie-points within that block when the triangulation is accepted.

Therefore, the extent to which either DEM program reproduced the elevation values for those points on its surface would be an objective evaluation of its accuracy. Each point in the block that had a pixel value range of 1.2 meters or less within a one-meter buffer of its position on both DEMs was queried and the delta error (absolute value) calculated between each DEM and the assigned elevation for that point within the block.

The mean delta for the ERDAS model is closest to the Total Image Unit Weight RMSE for the original block file ( 0.4546 pixels), indicating that it is the best translation of the triangulation. The TERREST model is considerably worse, which is consistent with visual assessments of the 1-meter and $15 \mathrm{~cm}$ TERREST DEMs that show smearing of the surface and artifacts with no apparent source in the imagery (Figure 3). However, the TERREST images were not geo-referenced and had to be registered to the ERDAS image for this comparison. The scaling was not proportional and required a second 
order warp to achieve a reasonable fit. This could be a source of error in the analysis, but it is also an additional problem with the TERREST data.

\section{Analysis of height differences between 2006 and 2002 ERDAS DEMs}

Figure 4 shows a detailed portion of those DEMs over one of these ring sites and it illustrates the differences between the $50 \mathrm{~cm}$ ERDAS images as compared to their corresponding $15 \mathrm{~cm}$ TERREST images.

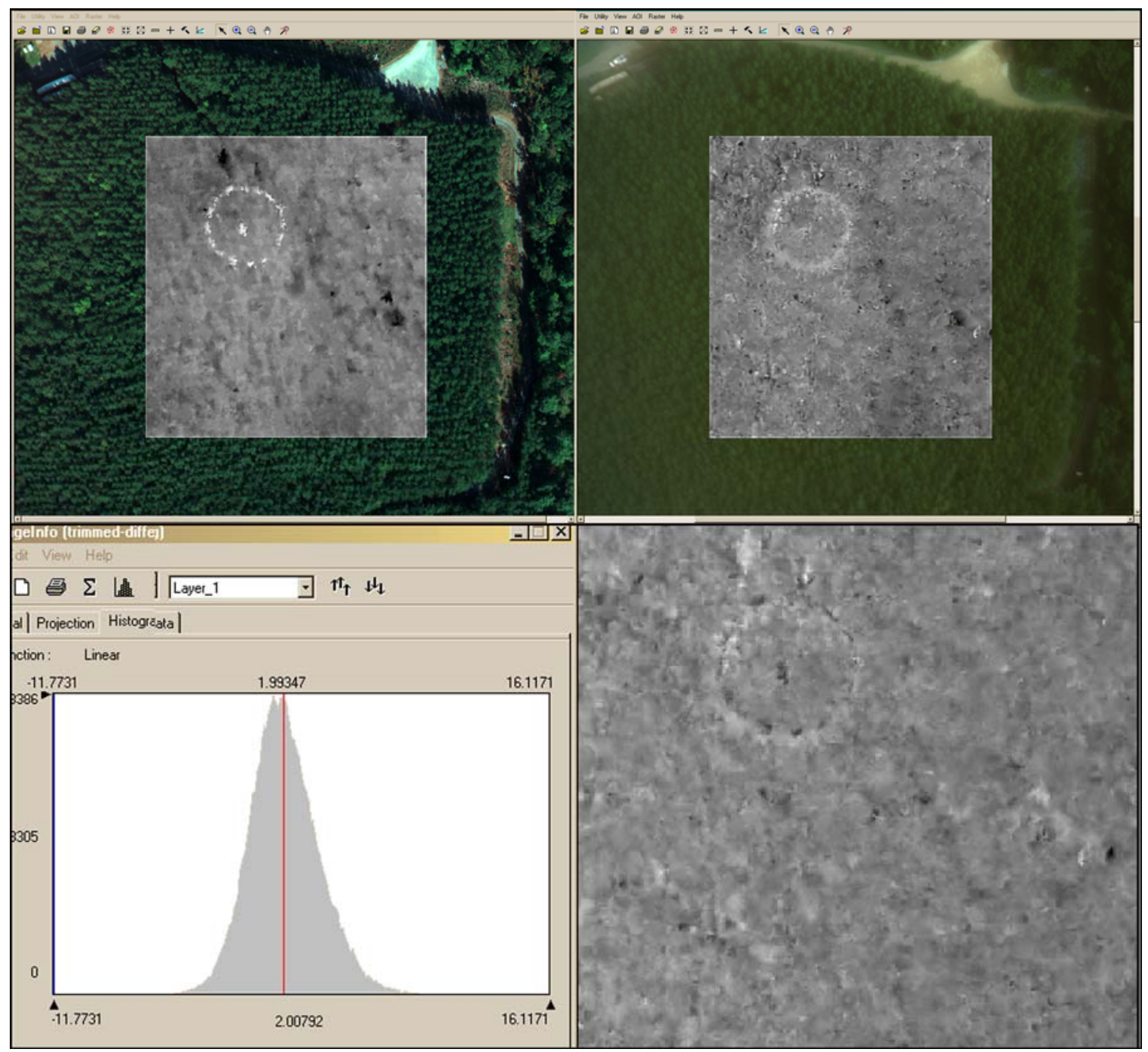

Figure 4. The 2002 (left) and 2006 (right) $50 \mathrm{~cm}$ ERDAS DEMs were trimmed to a section of the Loblolly Pine stand for a direct comparison of tree height. A difference file subtracting the 2002 model from the 2006 model (lower left) has a mean difference of two meters, which is consistent with Duke's on-site measurements. 
Comparing the 2002 ERDAS surface to its TERREST counterpart, the continued effect of longitudinal smearing and striping is apparent. Although the TERREST DEM retained the $15 \mathrm{~cm}$ pixel size of the original imagery, the discernable detail in the crowns and towers is actually less than the $50 \mathrm{~cm}$ ERDAS DEM. TERREST, which uses each band and all overlapping imagery for any point, actually appears to do a better job in retaining elevational detail in the 2006 imagery. If the striping and smearing can be resolved, it may prove to be the more robust program.

Once registration between the two DEMs had been established, a difference file was generated over a portion of the stand canopy and the mean height change calculated. That value of 2-meters growth over the four-year period is consistent with Duke's measurements and estimates for the stand, demonstrating the potential to measure stand level height change as a means of measuring carbon stock change.

While this study was intended to evaluate stand level change, we also examined changes in individual tree heights indicated by the difference file. If individual elevation points are identified on top of trees within the six meter range of tree heights in the 2002 DEM then matched to their corresponding points on the 2006 DEM, the results indicated that the shorter a tree was in 2002, the more it had grown by 2006.

The sequence over the FACE site is some of the best imagery in the 2006 coverage, with the camera under open sunlight and level. ERDAS LPS 9 is clearly able to produce a more accurate DEM than TERREST, which is an experimental process with remaining issues of image smearing, striping and elevation inaccuracy. However, the TERREST program appeared to extract more information and have fewer problems with artifacts when reproducing a surface from the 2006 imagery. In the long run, the TERREST approach may prove to be a more robust processor of marginal data than ERDAS.

\section{Duke Forest ground-based estimates.}

Duke Forest growth data were used with permission from the three FACE rings examined in detail $(2,4$, and 6$)$ that were also covered by the two sets of imagery. These rings were used because they eliminated major errors in georeferencing due to the ability to georeference to the FACE towers themselves. Live trees measured in late 2002 and late 2006 were used in the analysis; trees that died between these two time periods were excluded from both datasets. Aerially derived values were taken from a segmentation of the site with values inside the three FACE plots determined using the FACE towers as the outer boundaries and clipping these plots from the imagery. FACE biomass plot values were calculated for each age using the following equation form from Jenkins et al (2004):

$$
b m=\operatorname{Exp}\left(\beta_{0}+\beta_{1} \ln d b h\right)
$$


The intercept and slope values used for hardwoods and pine were:

$\begin{array}{llll}\text { Species Group b } & \text { Parameter } & \\ & \beta 0 & \beta 1 & N \\ \text { Mixed Hardwood } & -2.4800 & 2.4835 & 289 \\ \text { Pine } & -2.5356 & 2.4349 & 331\end{array}$

Per ha values were calculated from these $15 \mathrm{~m}$ radius plots by multiplying the area by an expansion factor of 14.15. Carbon was calculated as $0.5 \times$ above ground biomass (dry weight).

On average, the aerial-based measurements produced carbon estimates that were approximately $18 \%$ lower for the pine component compared to the ground-based estimates. A t test of these arrays demonstrated no significant difference at $p=0.05$.

Table 4. Aerial $x$ ground based above-ground carbon growth estimates for Duke Forest plots

\begin{tabular}{|c|c|c|c|c|}
\hline \multirow[t]{2}{*}{ Plot } & \multicolumn{2}{|c|}{ Aerial based } & \multicolumn{2}{|c|}{ Ground based } \\
\hline & $\begin{array}{c}\text { Mean } \\
\text { (t C ha-1) }\end{array}$ & $\begin{array}{c}\text { MAI } \\
\text { (t C ha-1 yr-1) }\end{array}$ & $\begin{array}{c}\text { Mean } \\
\text { (t C ha-1) }\end{array}$ & $\begin{array}{c}\text { MAl } \\
\text { (t C ha-1 yr-1) }\end{array}$ \\
\hline 2 & 16.7 & 4.2 & 20.3 & 5.1 \\
\hline 4 & 14.7 & 3.7 & 19.7 & 4.9 \\
\hline 6 & 12.2 & 3.0 & 13.1 & 3.3 \\
\hline Mean & 14.5 & $3.6(.17)^{a}$ & 17.7 & $4.4(.22)^{a}$ \\
\hline
\end{tabular}

When these the carbon stocks are conservatively estimated from these two arrays using the Reliable Minimum Estimate (RME) (MacDicken, 1997) for carbon stock reporting, these MAI differences are even smaller: $\mathrm{RME}_{\text {aerial }}=2.6 \mathrm{t} \mathrm{C} \mathrm{ha}^{-1} \mathrm{yr}^{-1}$ and $\mathrm{RME}_{\text {ground }}=2.8 \mathrm{t}$ $\mathrm{Cha}^{-1} \mathrm{yr}^{-1}$

Height assessment methods were also compared - using the aerial imagery and DEM compared with the ground measurements from FACE. FACE rings were used as plots, the manual treatment was taken from a 3D analysis by Silvia Petrova, while the ground derived heights were taken from FACE project records for same plots taken within 4 weeks of imagery. Loblolly pine dominates these well-stocked stands.

An analysis of variance (Table 5) shows that the plot $x$ methods interaction is significant with differences between methods of between $0.4 \mathrm{~m}$ and $5.8 \mathrm{~m}$ for trees that average $16.5 \mathrm{~m}$ in height. The difference in height determination from the two methods varied across these fixed area plots. Manual 3D methods were highly variable - with measurement errors of between $3 \%$ and $40 \%$ of the total height. 
Table 5. Analysis of variance table for height measurement methods at Duke Forest

\begin{tabular}{lrrrrl}
\hline \multicolumn{1}{c}{ Source } & Sum-of-Squares & Df & Mean-Square & F-ratio & P \\
\hline PLOT & 78.66 & 2 & 39.33 & 26.87 & 0.00 \\
METHOD\$ & 129.49 & 1 & 129.49 & 88.47 & 0.00 \\
PLOT*METHOD\$ $_{\text {Error }}^{395.90}$ & 2 & 197.95 & 135.24 & 0.00 \\
\hline
\end{tabular}

\section{AEP Avondale Wildlife Area, Ohio}

The AEP Avondale Wildlife Area is approximately 5,423 acres of managed forestlands in central Ohio that are part of American Electric Power's (AEP) Forestry portfolio (Figure 5). The 2003 coverage was flown with Winrock's M3DADI external camera pod attached to a local 172 Cessna aircraft out of the Zanesville Airport. Four-band multispectral imagery was captured with the Duncantech M4100 high definition video camera in a grid of flight lines that provided complete stereo coverage of the site at a scale of $25 \mathrm{~cm}$ per pixel. In July 2006, Winrock re-flew approximately 1800 acres of the Avondale site at $15 \mathrm{~cm}$ per pixel resolution with the same Duncantech camera and the 5-band profiling laser. All deliverables and analysis for this section of the report come from the two sets of photography over that portion of the property. 


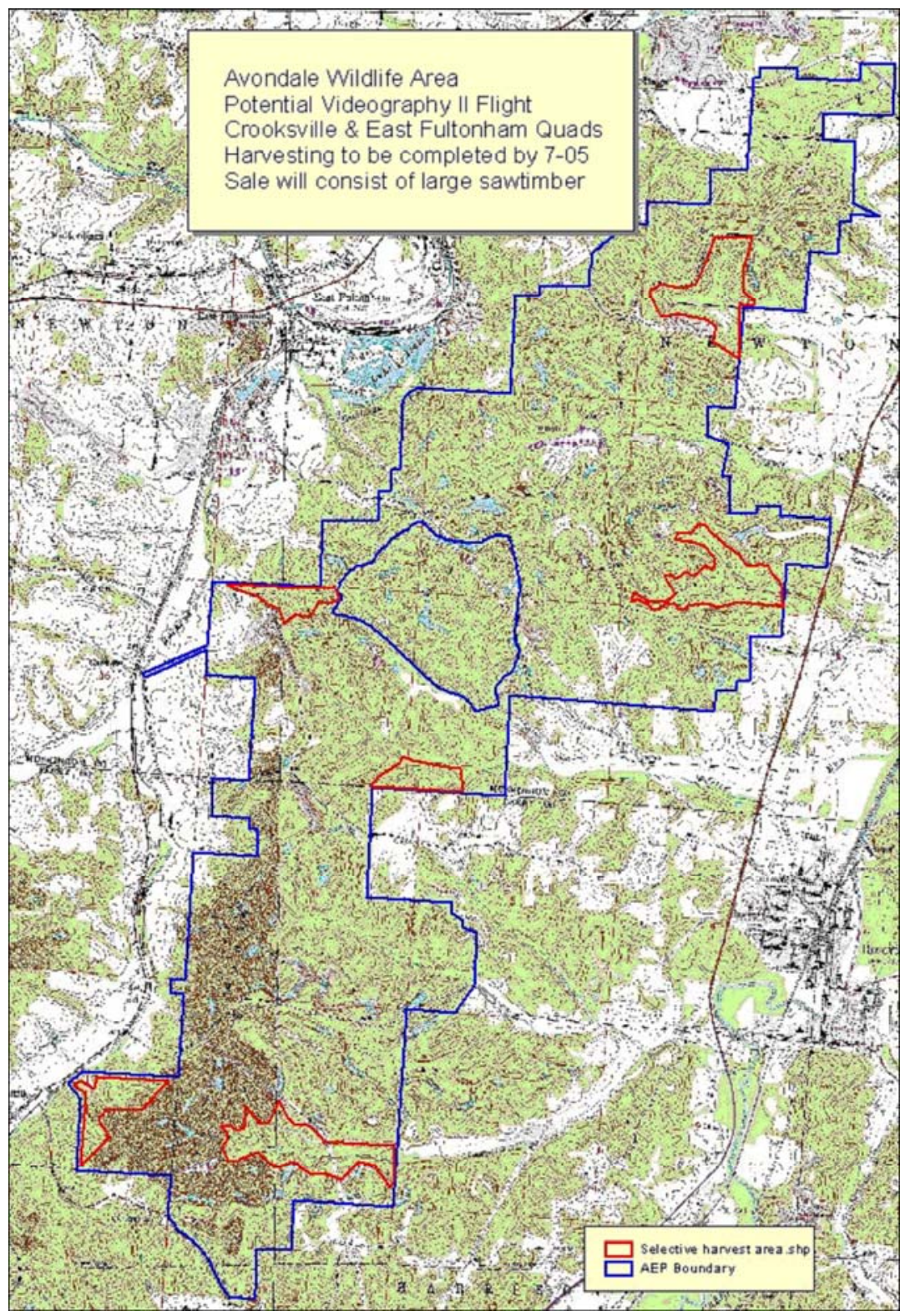

Figure 5. AEP Avondale Wildlife Area, showing harvest areas selected in 2003 


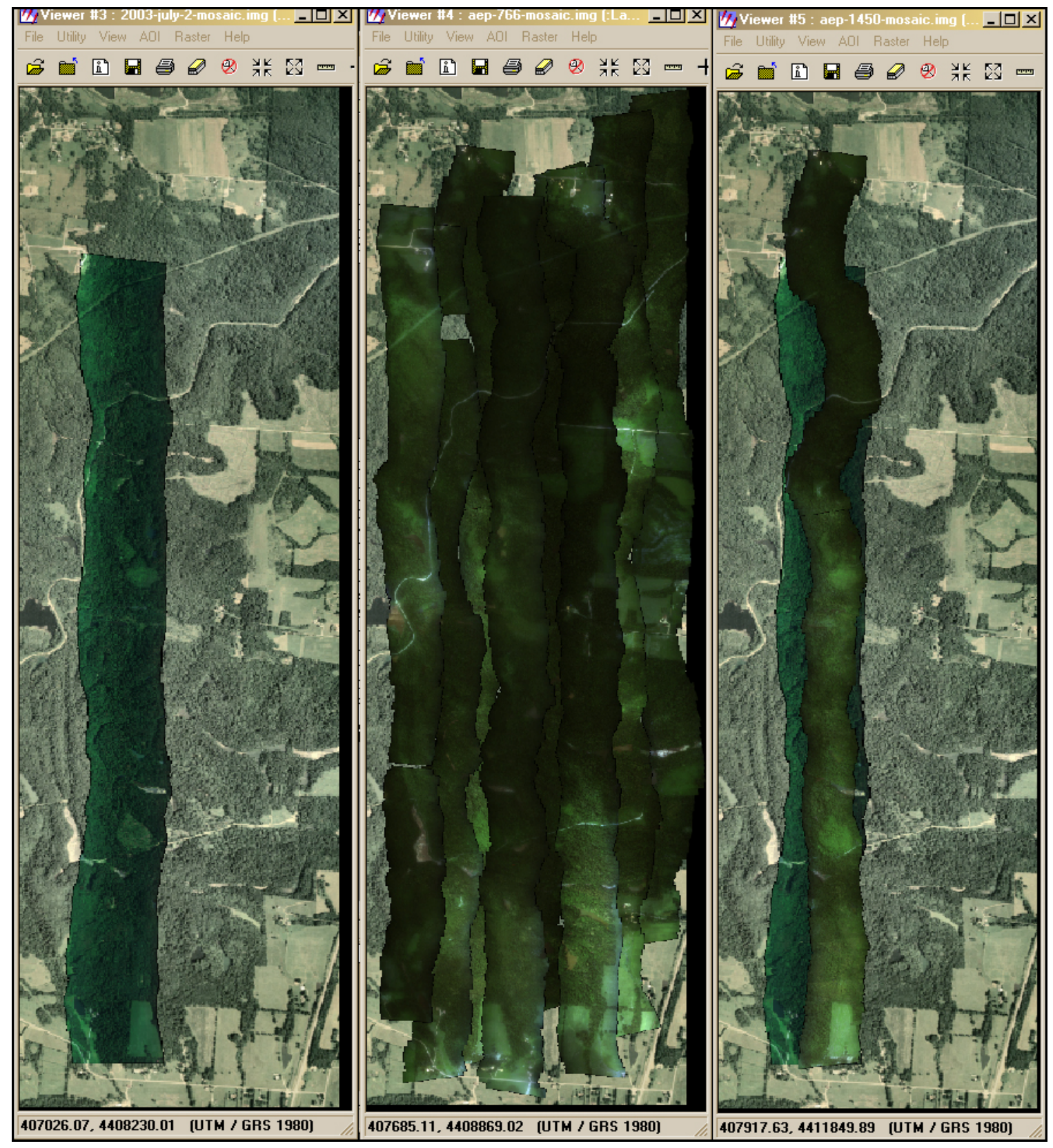

Figure 6. One flight line of the original 2003 Avondale coverage (left) was available for comparison with the 2006 coverage (center). Approximately 2000 acres of 2006 imagery was processed to block files and DEMs, but only the corresponding flight lines (right) were used in analysis.

Unlike the carefully surveyed Blackwood Division of the Duke Forest, this site had no ground information other than data readily available from State repositories and commercial GIS venders on the Internet. The principal objective of this analysis is to compare the available multi-temporal data of the Avondale Wildlife Area and develop difference surface models to determine both changes in stand height and the extent to which selective logging sites can be identified from Time 1 to Time 2 with the metrics of individual removed trees measured in 3D using ERDAS Stereo Analyst. 


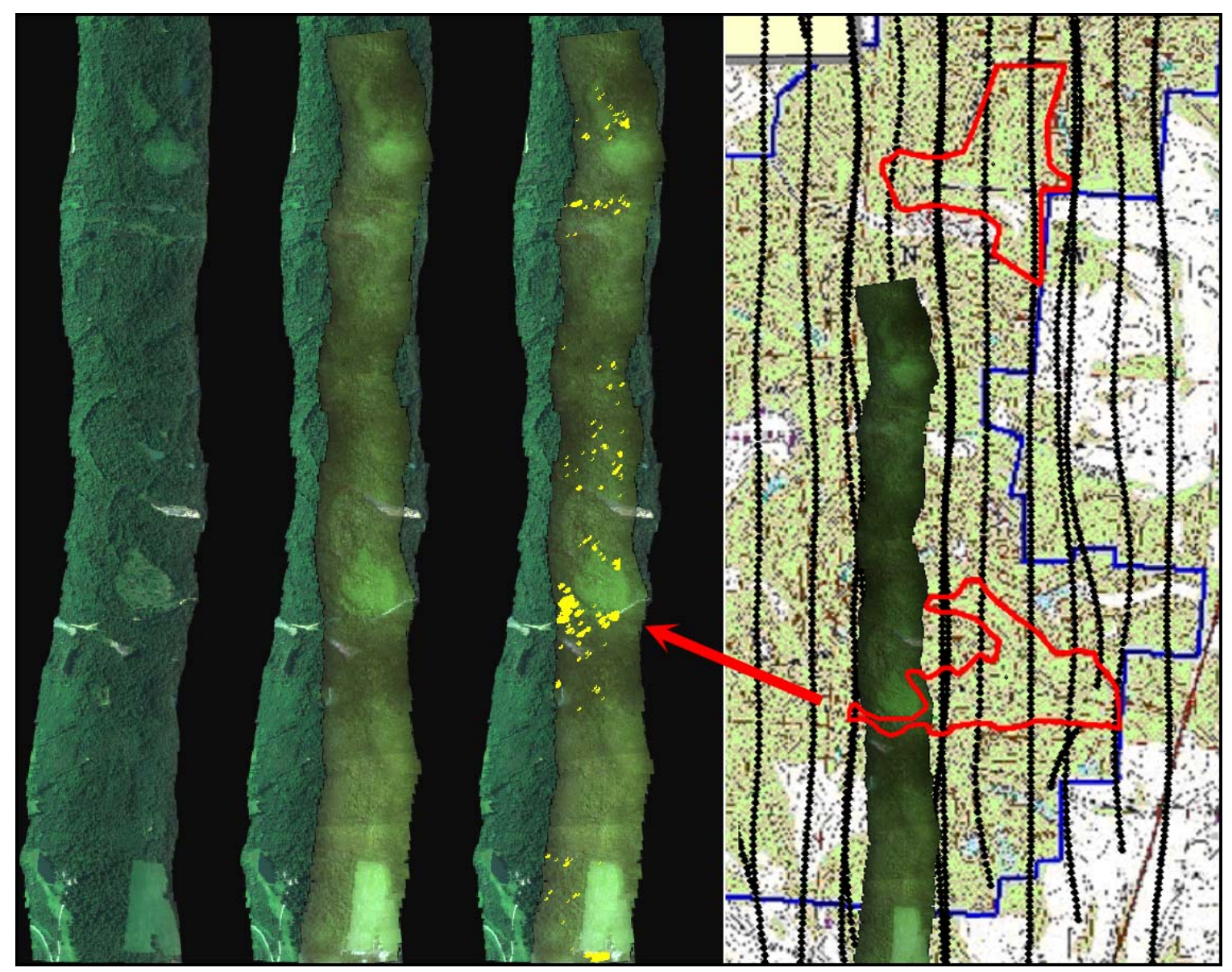

Figure 7. A change detection overlay (right mosaic) between Time 1 (2003, left mosaic) and Time 2 (2006, center mosaic) identified removed trees in the only section of the selected harvest sites that the 2006 imagery covered. 


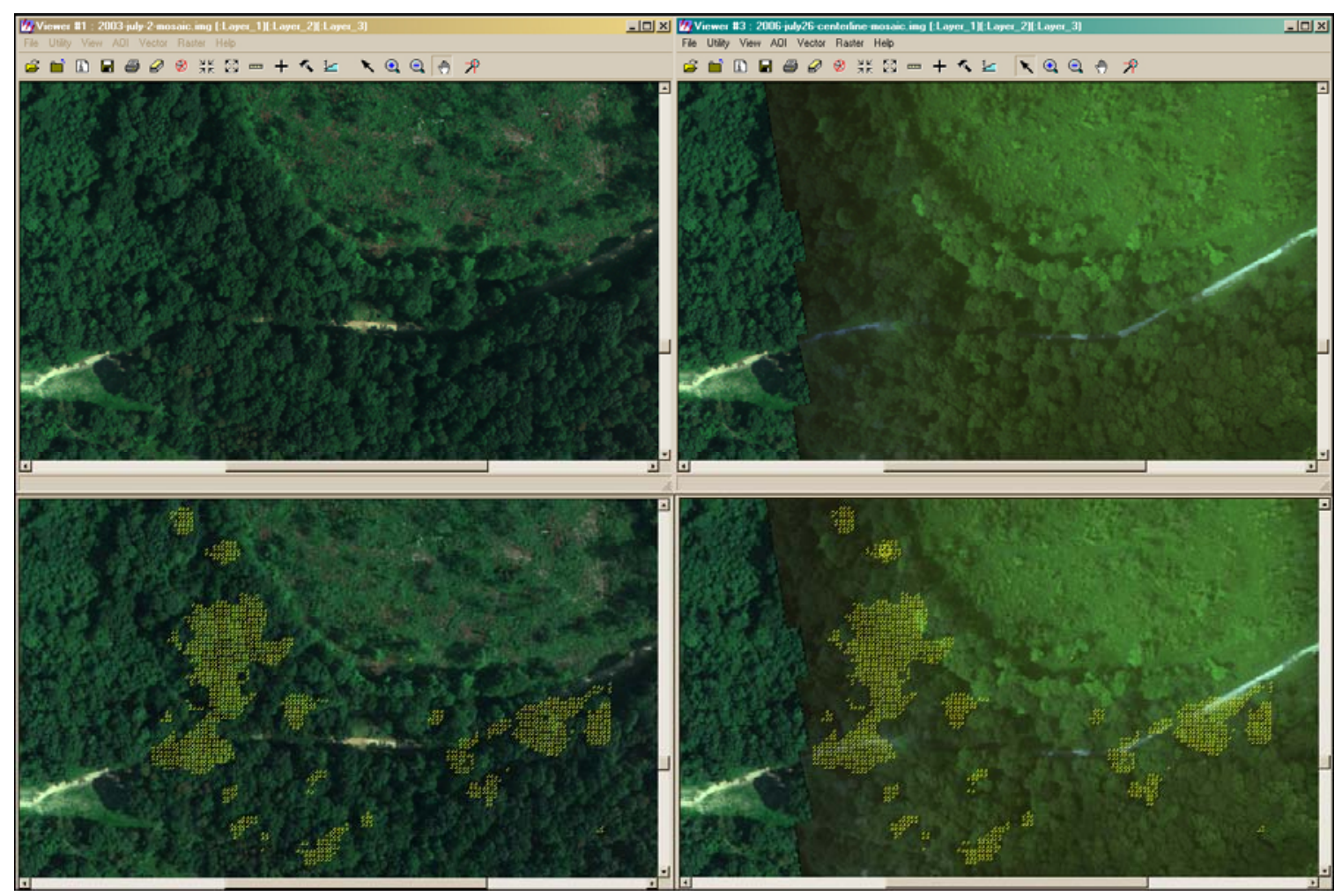

Figure 8. Because some vegetation has grown back over the gaps left by tree removal, it would be very difficult to identify them on the 2D views of the 2006 images (left) without reference to the change detection overlay in yellow and the 2002 coverage (right).

\section{Analysis of height differences between 2006 and 2002 ERDAS DEMs}

Identifying gaps in a forest canopy caused by selective logging is a coarser assessment than measuring changes in stand height and the 1-meter 2006 DEM registered to the existing 2002 flight line was sufficient for this purpose. Success in this type of semiautomated change detection is achieved by isolating the changes most likely to result from commercial tree removal. In this case, the difference file was converted to ESRI coverage and edited for groups of elevation points greater than 4 meters across with negative values equal to or less than -10 meters.

The 2006 flight line-3A covers one corner of a proposed selective harvest site provided by AEP and removed trees were successfully identified in that area. These gaps were several years old with new vegetation on the ground, so it would have been difficult to identify them by spectral classification or visual inspection without elevation change detection (Figure 7).

Once these gaps could be verified by visual inspection in stereo (Figure 34), the height and crown diameter were measured on the pre-logged 2003 coverage using a featuremapping project in ERDAS Stereo Analyst (Figures 35 and 36). With the soon-to-beremoved trees identified by the difference point coverage, crown diameter, maximum elevation and associated ground elevation points were recorded as 3D polygon and 
point shapefiles. The point shapefiles that measured crown and ground elevation were attributed to the crown diameter polygons in ERDAS to create a table for each tree that identifies its height and crown area (Table 3).

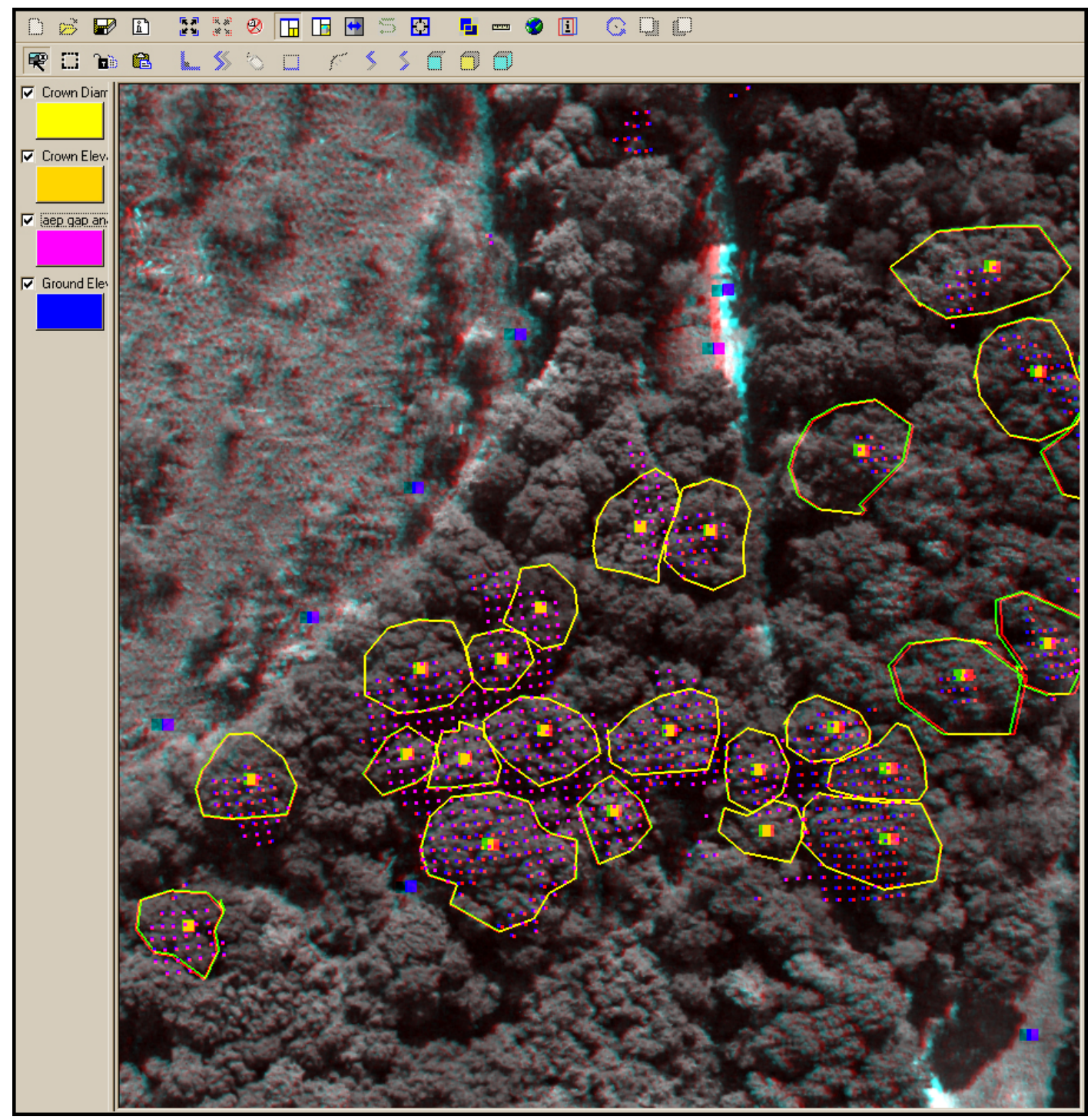

Figure 9. Soon-to-be-logged trees are identified by laying the change detection point file over an epipolor pair of 2003 images in ERDAS Stereo Analyst. Crown diameters and maximum elevation are recorded as 3D shapefiles in a feature-mapping project with ground elevation where possible (requires red/blue glasses for stereo viewing).

$52 \%$ of the difference file values produced by subtracting the 2003 DEM from the 2006 DEM fall between minus four meters and plus four meters. When separated into 1meter ranges and displayed over an ortho-mosaic of the 2003 flight line, the positive values show some correspondence to the type of changes in tree height that might be expected in temperate forest canopy (Figure 10 upper half). However, when the negative range of values between zero and -4 are added, they dominate the image, particularly on open ground (Figure 10 lower half), which indicates poor elevational 
registration between the two models. Since the 2006 imagery was registered directly to the 2003 DEM and ortho-mosaic in block construction, this may be a function of its more diffuse resolution, low contrast or higher Omega values.

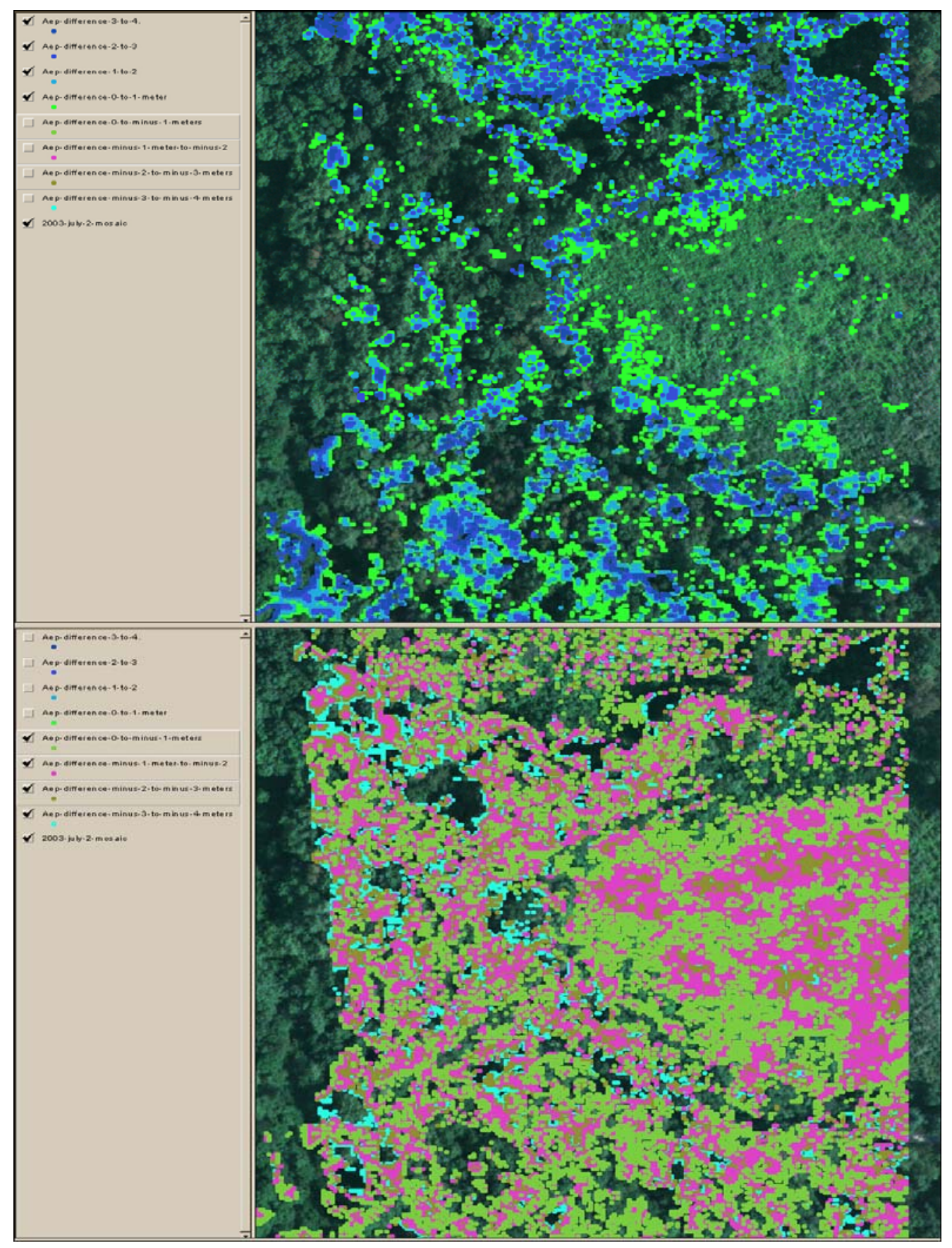

Figure 10. When positive changes in the difference file created by subtracting the 2003 DEM from the 2006 DEM are extracted as 1-meter ranges between 0 and 4 meters, (top ArcView), they could appear to be modeling changes in the canopy without affecting the open non-vegetated areas. 


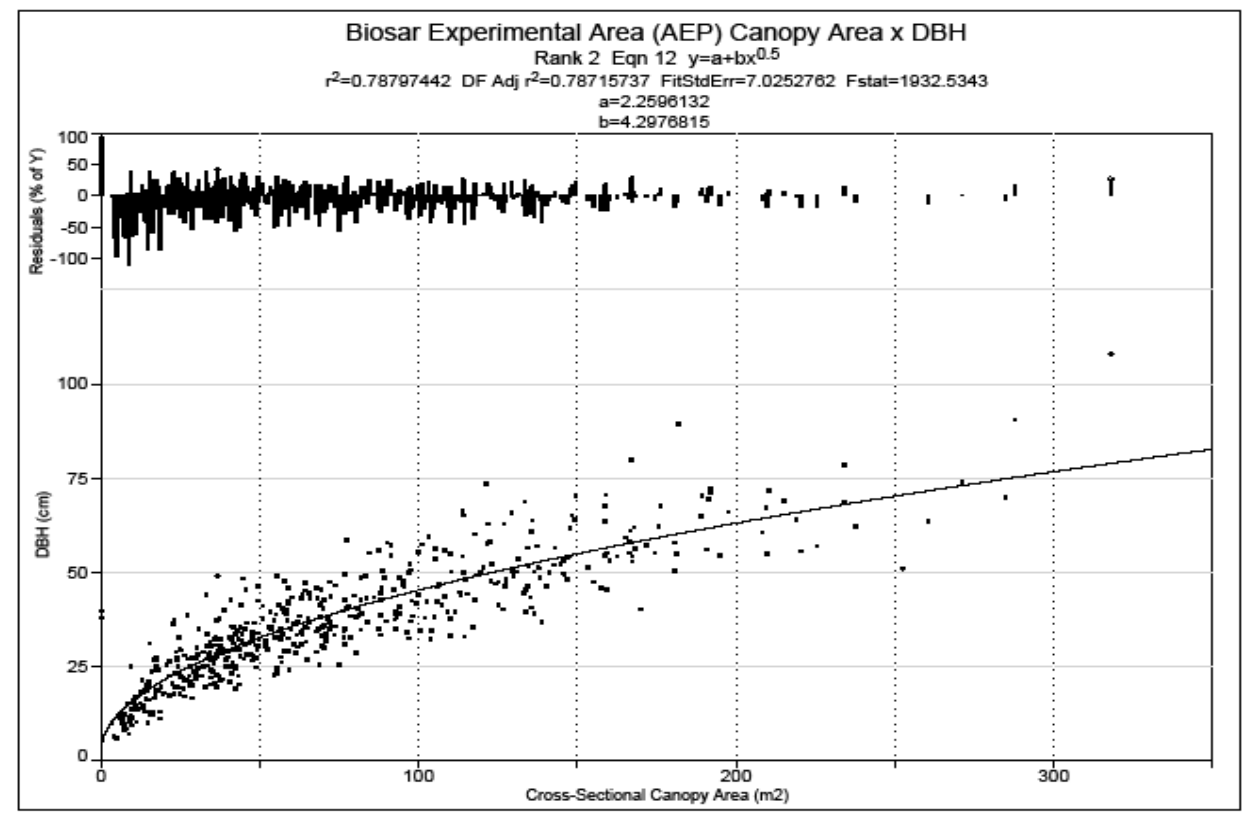

Figure 11. Cross-sectional canopy area by DBH relationship used in converting aerially-derived canopy segments to DBH

\section{AEP ground plot results}

The general biomass equation used by AEP (Brown et al) produced higher biomass estimates for younger age class stands than did the estimates generated using a species group-specific equation (Jenkins 2004). This relationship crossed-over at a median stand age of approximately 65 years, with the general biomass equation producing lower carbon in the older age classes. No destructive sampling was done through this project to evaluate the relative ability of these two models. The Jenkins forest-type specific model was used in these analyses because of the more relevant dataset used in model construction - NE hardwoods as opposed to the global dataset used for Brown et al.

Plot to plot variability ranged from CV of 19 to $42 \%$ (Table 4). Variability also tended to decrease with increasing age class (Figure 12), although this relationship was influenced by a smaller number of more homogenous plots in the 85 year old age class. 


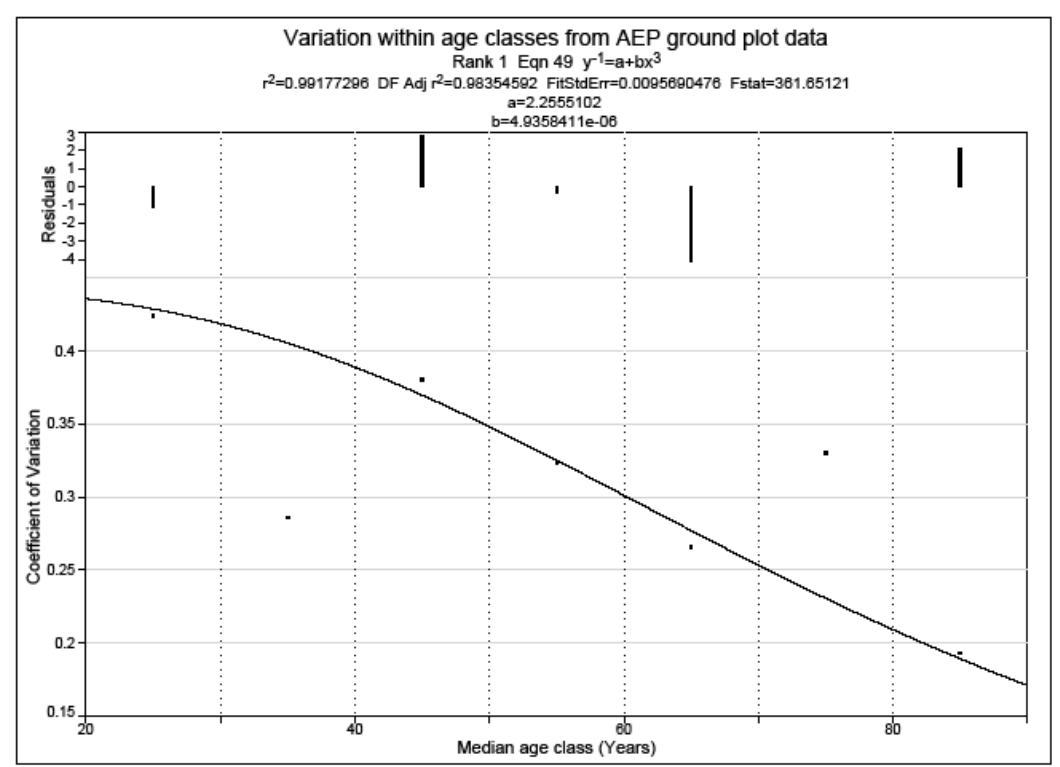

Figure 12. Age class $x$ variability relationship at AEP site

The commercial desk-top software eCognition professional 4.0 was used to map and measure tree crowns in a portion of what is known as the 'Biosar' area of AEP's Muskingum Mine property (Fig. 13). This area was chosen because AEP foresters had good data available on the ages and compositions of the tree stands. A sub-set of the Biosar area was analyzed because of either software and memory constraints or cloudy weather which prohibited $100 \%$ coverage of the property.

The objective of the analysis was to analyze the relationship of tree crown area measurements taken from the imagery to field-based measurements in red oak and yellow poplar tree stands (Fig. 14a). This was done by applying spectral reflectancebased object segmentation to a subset of the aerial imagery mosaics over the Biosar area (Fig. 15). 


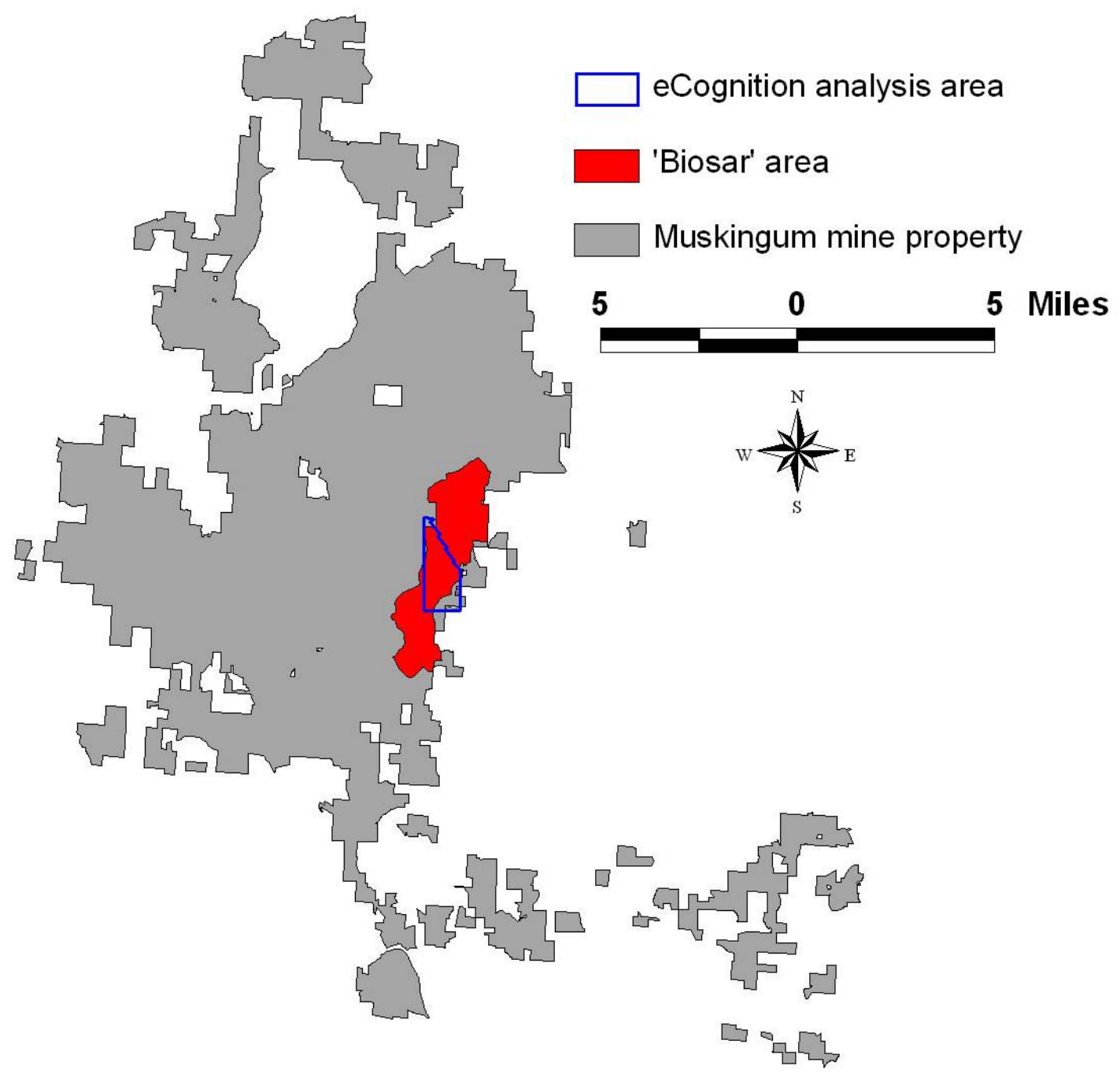

Figure 13. The 1000-acre eCognition study area (blue) against the greater Muskingum Mine area (grey) and 'Biosar' study area (red). 
(a)

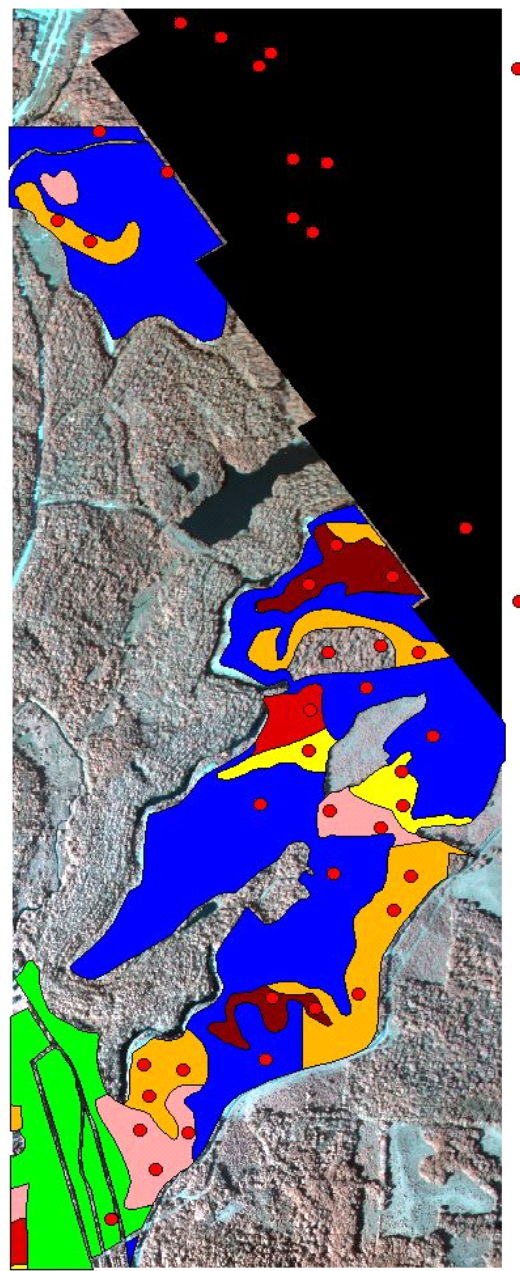

0.5

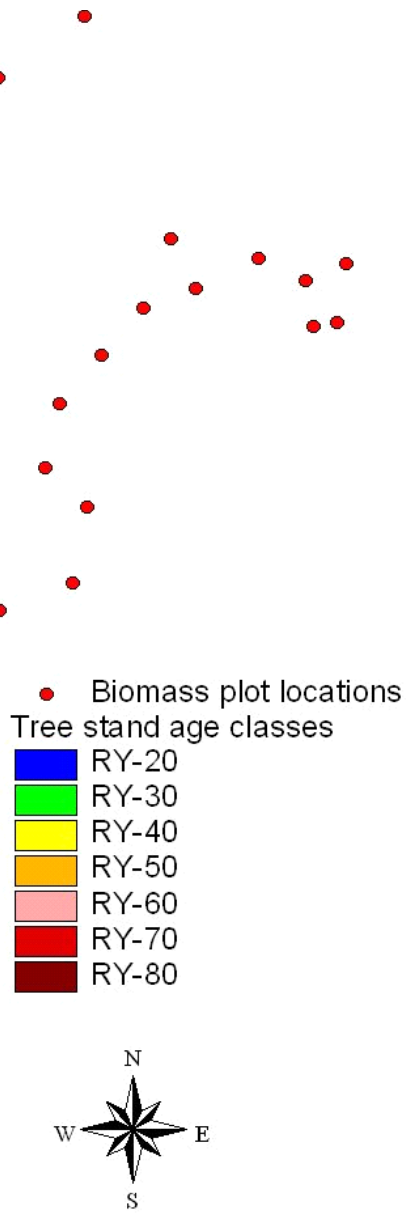

0.5 Miles (b)
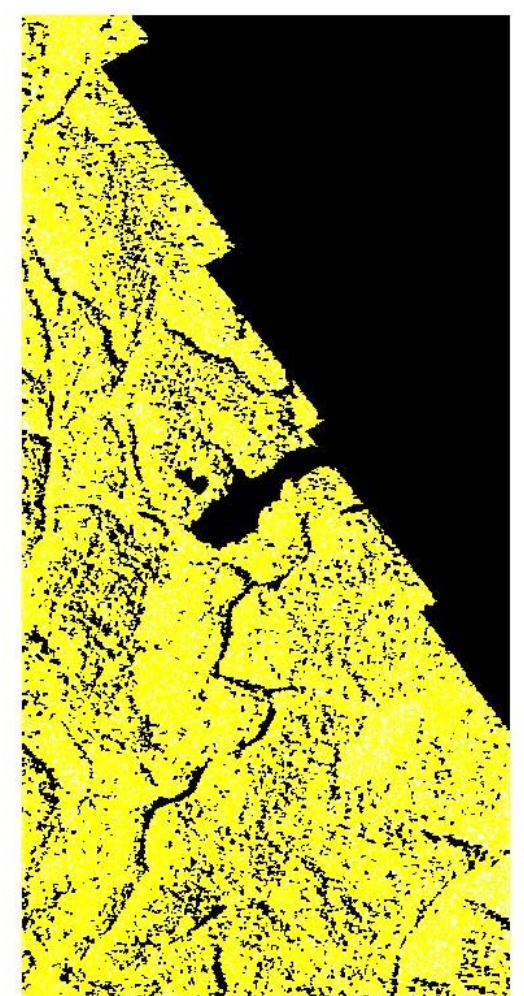

Image cla sha

Figure 14. (a) The red oak-yellow poplar (RY) tree stand age classes as mapped by the AEP forestry division. (b) The segmented forest canopy in the study area.

Segmentation is the process of breaking the image reflectance values and contiguity relationships and using them as the basis for a delineation of polygons with different land-cover classes attributed to them. The tree crown areas are measured from the tree-classified polygons or 'segments'. 


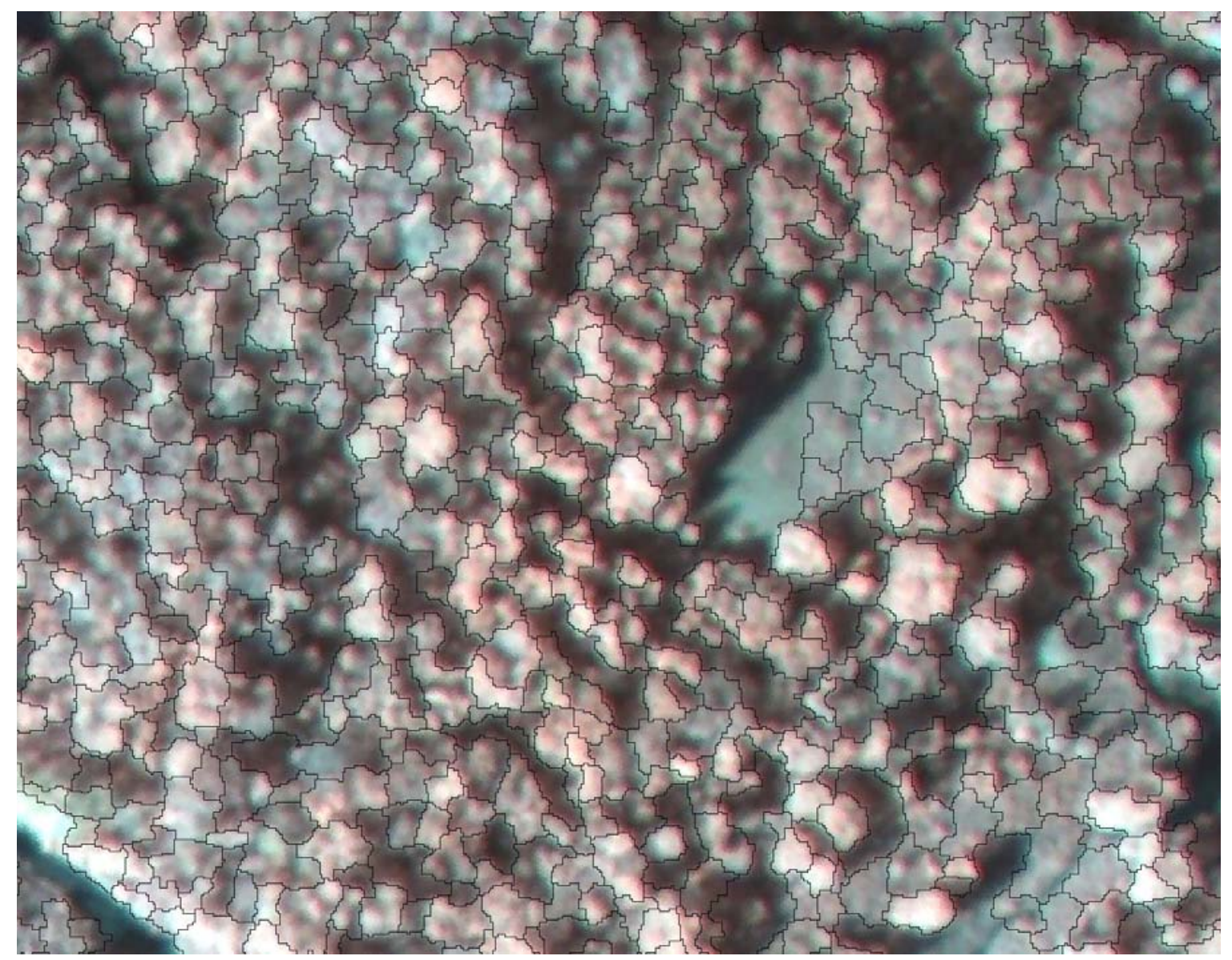

Figure 15. A close-up view of tree canopy segmentation in the Biosar area.

With crown area measurements and field-based allometrics on the relationship of crown area to diameter at breast height, biomass estimates can be made. The classification that was applied in this area included 5 classes and they are listed below with their classification-rule details:

- shadows (band2 reflectance monotonically decreasing to a 122.25 asymptote with an inflection point at 61)

- bare ground or water (NDVI value monotonically decreasing from 0 to a 0.07 asymptote with an inflection point at 0.035 )

- grasses and low vegetation (NDVI value monotonically decreasing from a -0.025 upper asymptote to an inflection point of 0.1 and a 0.225 lower asymptote)

- young, sparse or plantation trees (areas not already classified as 'grasses and low vegetation' with a band 1 ratio value monotonically decreasing from an upper asymptote of 0.402142 , hitting and inflection point at 9.438571 and a lower asymptote of 0.475$)$.

- deciduous trees (band 1 ratio value monotonically increasing from an lower asymptote of 0.31 , hitting and inflection point at 0.391423 and an upper asymptote of 0.472846 ).

The classification is shown in Figure 16. 


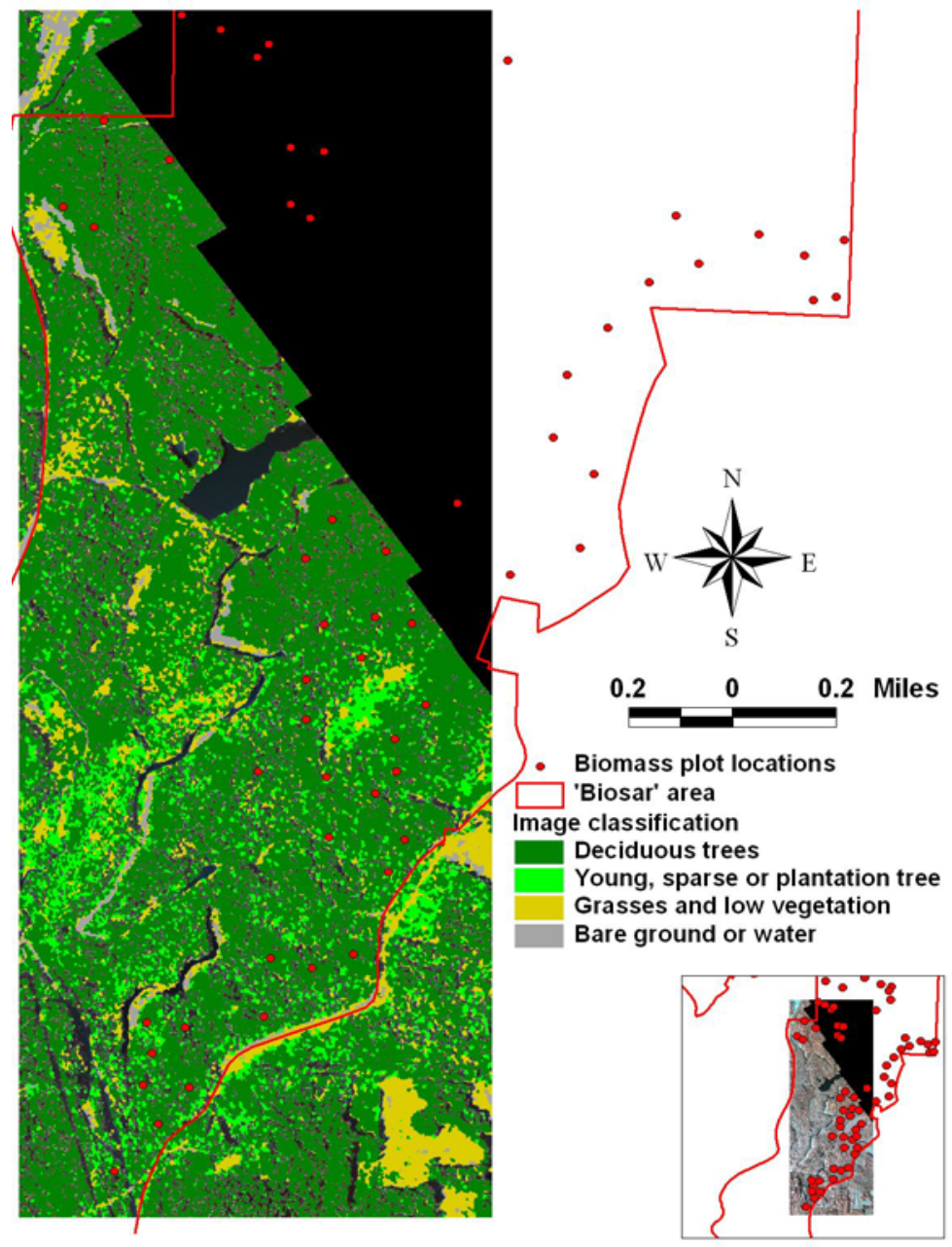

Figure 16. The full classification of the Biosar area study area subset.

A close-up example of how the classification results looked is shown in Figure 17.

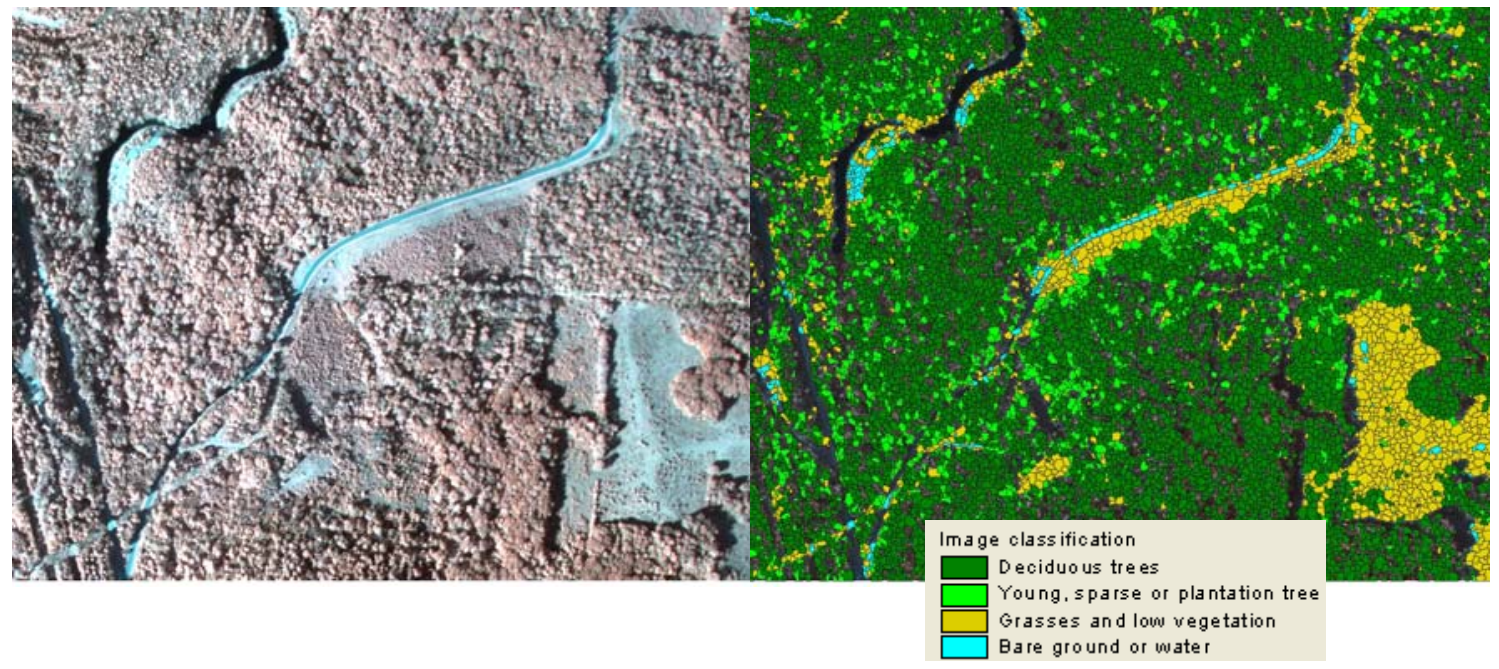


Figure17. Classification example 1 from the eCognition analysis.

One 10-acre field within the study area was classified as predominantly 'young, sparse or plantation trees' although, some areas of 'grasses and low vegetation' also came through in the classification. This is an area which was planted with predominantly white pine in 2000 . The eCognition analysis, when calibrated with the correct variables can yield valuable information on the locations of different species and recently planted areas such as these white pine while survival rates can also be assessed from the 2000 planting. In the areas classed as 'grasses and low vegetation' some conclusions can be drawn about the remaining trees and biomass there. The 'grasses and low vegetation' and 'bare ground or water' classes totaled approximately 1.9 acres while the combined tree classes of 'deciduous' (possibly erroneous) and 'young, sparse or plantation trees' totaled 8.0 acres. Shadows rounded out the remaining area (Fig. 18).
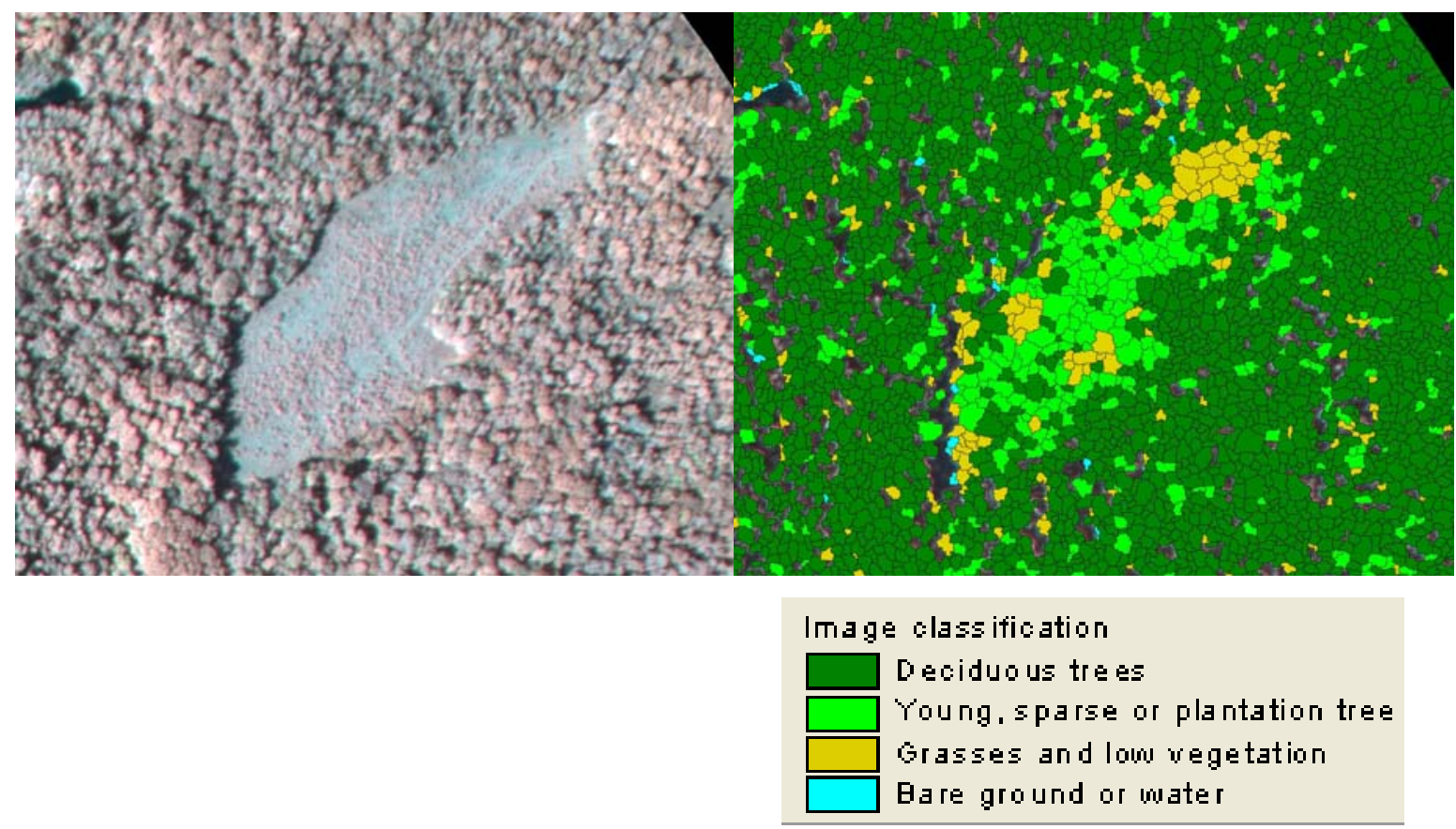

Figure 18. Classification example 2 from the eCognition analysis. Reforested areas classified with eCognition as 'young, sparse or plantation trees' or 'grasses and low vegetation classes'.

When the areas of these crowns in the segmented red oak and yellow poplar stand are charted in histograms (Fig. 18), it can be seen that the distributions do gradually shift to the right (larger area) as the stands get older. Certainly the proportion of large trees can be seen to increase with stand age. believe that the presence of remnant trees in the younger age-class stands may be what causes the histograms and overall means of the 20-, 40- and 50-year stands to be stand out as they are. Visual spot inspections of the delineated stands do not show overwhelming differences in tree crown sizes between stands. The large tree crowns mapped in the younger-aged stands often stand out as evidence supporting this assertion (Fig. 19). 


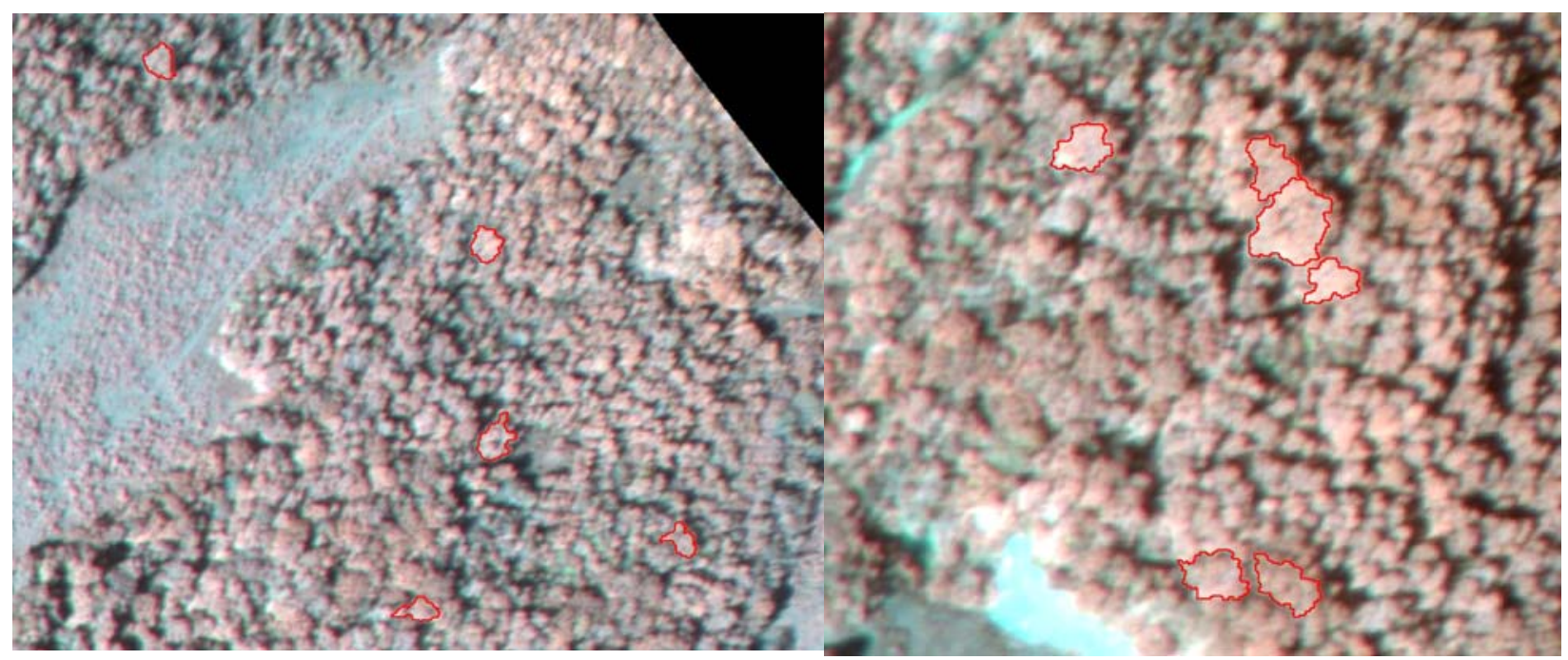

Figure 19. Examples of trees in stands mapped as RY-20 that exhibited cross-sectional crown areas $>200 \mathrm{~m} 2$.

While the segmentation process is not perfect, it does seem that the presence of relic trees of older ages or sizes is responsible for the counter-intuitive distribution of mean crown areas. Errors can be made by the software in its ability to consistently map tree crowns in adequately-sized segments: segments too small, cutting tree crowns into pieces or are too large encompassing multiple trees in one segment. Trends in these errors are discussed at some length later in this report. This research also indicated that some differences in the tendency of the software to map segments of difference sizes is based on the manual and almost arbitrary input of a 'scale' factor variable into the software runs. Through multiple iterations, the scale factor can be adjusted to adequately capture the crowns in a specific area but in heterogeneous areas where multiple size-classes are found, this can be problematic.

\section{Assessment of automated classification methods for determining canopy objects}

We used three approaches to assess the value of automated classification methods: 1) comparison of ground and aerial data in AEP lands in the Biosar Experimental area in Ohio; 2) analysis of DEM-matched pairs in the Avondale Wildlife Reserve area of AEP in Ohio, and; 3) stereo pair assessment of segments and classification of segmentation errors.

The results of the comparison of ground and aerial data on AEP lands in the Biosar area demonstrate the need for both high quality imagery/georeferencing and good field mapping (Table 6). When applying these carbon stock estimates in these stands, the total carbon stocks calculated across the 156 hectares (386 acres) of forest within the aerial study area differs substantially. The total stock of carbon calculated using the adjusted aerial measurements is approximately $8,900 \mathrm{tC}$ while the adjusted field measurements and calculations yield approximately 10,600 t C -an approximate difference of $1743 \mathrm{t} \mathrm{C}$. 
Table 6. Comparison of carbon measurement results from aerial imagery classification/segmentation vs. field measurements in the Biosar experimental area. For the aerial measurements, $\mathrm{t} \mathrm{C/ha}$ is initially calculated using a general equation for eastern US hardwoods (Jenkins et al 2004 ) and for all land-cover types within the stands. It is thereafter adjusted to show estimates just for the areas within the stands classified as deciduous trees. For the field-based measurements, tree data are initially summarized using tree species-specific equations and thereafter using the general equation (both from Jenkins et al).

\begin{tabular}{|c|c|c|c|c|c|c|c|c|c|}
\hline \multirow[b]{2}{*}{ Stand } & \multirow[b]{2}{*}{$\begin{array}{l}\text { Stand area } \\
\text { (ha) }\end{array}$} & \multicolumn{3}{|c|}{ Aerial measurements } & \multicolumn{5}{|c|}{ Field measurements } \\
\hline & & $\begin{array}{l}\text { Hardwood } \\
\text { crown area } \\
\text { from aerial } \\
\text { (ha) }\end{array}$ & t C/ha & $\begin{array}{l}\text { adjusted t } \\
\text { C/ha }\end{array}$ & $\begin{array}{l}\text { Number } \\
\text { of field } \\
\text { plots }\end{array}$ & $\begin{array}{c}\text { t C/ha } \\
\text { (species- } \\
\text { specific) }\end{array}$ & C.V. & $\begin{array}{c}\text { t C/ha } \\
\text { (general) }\end{array}$ & C.V. \\
\hline RY-20 & 87.7 & $\begin{array}{r}66.3 \\
(75.5 \%) \\
10.1\end{array}$ & 43.4 & 57.4 & 18 & 55.8 & 0.43 & 53.1 & 0.45 \\
\hline RY-30 & 19.7 & $(51.1 \%)$ & 27.5 & 53.7 & 3 & 55.8 & 0.05 & 49.1 & 0.17 \\
\hline RY-40 & 5.1 & $\begin{array}{r}3.8(74.3 \%) \\
16.6\end{array}$ & 42.5 & 57.2 & 8 & 91.3 & 0.40 & 77.4 & 0.32 \\
\hline RY-50 & 22.7 & $(73.2 \%)$ & 41.6 & 56.7 & 21 & 115.1 & 0.30 & 93.2 & 0.27 \\
\hline RY-60 & 10.2 & $6.5(64.2 \%)$ & 35.4 & 55.1 & 18 & 132.9 & 0.38 & 113.6 & 0.38 \\
\hline RY-70 & 3.4 & $2.3(68.0 \%)$ & 38.6 & 56.8 & 10 & 132.5 & 0.26 & 109.3 & 0.24 \\
\hline RY-80 & 7.7 & $6(78.5 \%)$ & 45.2 & 57.4 & 5 & 142.9 & 0.42 & 123.8 & 0.43 \\
\hline
\end{tabular}


Table 7 demonstrates remarkable agreement between aerial plot and ground measurements a difference of $<3 \%$ between these two methods. Only five $10 \mathrm{~m}$ radius circular ground plots were collected in this area of Avondale and the five aerial plots of the same size were laid onto the same plot center coordinates. We assumed that while the same coordinates were used, they were not in the same location due to inherent error in image geo-referencing and GPS readings taken under forest canopy.

Of particular note is the agreement between aerial plots and ground plots including only trees above $20 \mathrm{~cm}$ dbh. Because the imagery does not see trees in the intermediate and suppressed canopy classes, we excluded smaller dimension stems from the ground-plots. There was a reasonable breaking point at $20 \mathrm{~cm}$, so we used this as the cutoff for inclusion in the ground based estimates. Assessing the most accurate cutoff diameter is an area of inquiry that needs attention in future work. Knowing this lower diameter limit would allow the inclusion of this small dimension carbon pool from limited ground measurement in the aerially-based wide area carbon estimates.

Table 7. Biomass comparisons for Avondale plot locations

\begin{tabular}{|l|r|r|r|r|}
\hline & \multicolumn{1}{|c|}{$\begin{array}{c}\text { Aerial } \\
\text { strip }\end{array}$} & \multicolumn{1}{c|}{$\begin{array}{c}\text { Aerial } \\
\text { plots }\end{array}$} & $\begin{array}{c}\text { Ground - all } \\
\text { diameters }\end{array}$ & \multicolumn{1}{c|}{$\begin{array}{c}\text { Ground } \\
\text { above 20 cm } \\
\text { dbh }\end{array}$} \\
\hline N (trees per ha) & 162 & 274 & 477 & 242 \\
\hline Mean (kg per tree) & 412 & 516 & 325 & 569 \\
\hline Area sampled (ha) & 9.3 & 0.16 & 0.16 & 0.16 \\
\hline $\begin{array}{l}\text { Total above-ground woody } \\
\text { biomass carbon (Mg C per } \\
\text { ha) }\end{array}$ & 48.6 & 70.7 & 77.7 & 68.7 \\
\hline
\end{tabular}

\section{Conclusions}

TERREST is capable of delineating loblolly pine crowns in a manner that cannot be matched by LPS. Unfortunately, TERREST does not translate a triangulated block of images as accurately as LPS. It has a wider range of error in the reproduction of elevation values and spatially distorts the model. Registration problems were minor with the LPS 2006 DEM and easily corrected with a simple affine transform to the 2002 image. Misregistration was more complicated with the TERREST images, which were spatially distorted from both their LPS counterparts and each other.

It may be impractical to attempt to measure the heights of individual trees over time until the microregistration issues are resolved, but stand level changes can be quantified as hypothesized in this project design. Segmentation and allometric-based estimates of standing carbon proved to be complimentary to ground-based plot sampling, show no statistically significant difference between aerial and ground-based measurements in either test site.

The differences between aerial and ground based methods are great when image quality is poor - as was the case with the 2006 Duke Forest imagery affected by an oil film on the lens. When image quality was high, such as in the Avondale imagery, the aerial plot and ground plot results for biomass were very close to one another. Wide coverage image analysis allows a major advantage over ground-based plots in that the imagery samples represent the true distribution 
of strata, which are only approximated using ground plots. This was particularly evident in the AEP site where stands recorded as even aged, fully stocked were seen to be less well stocked with uneven population densities. The automated analysis accurately classified these areas and provided a useful GIS-based set of results that could not be achieved using standard ground-based methods.

\section{Acknowledgements}

Financial support for this study came from the Dept. of Energy, National Energy Technology Laboratory, Terrestrial Sequestration Program, American Electric Power and Winrock International, for which we are grateful. We also would like to thank Dr. Jim Clark, Mike Wolosin, Dr. Ram Orin and Jeff Pippen at Duke University and Gary Kaster and the American Electric Power Company for data access and on the ground assistance. 


\section{Literature Cited}

Baltasavias, E., Favey, E., Bauder, A., Bösch and H., Pateraki, M. 2001. Digital Surface Modelling by Airborne Laser Scanning and Digital Photogrammetry for Glacier Monitoring. Photogrammetric Record, 17(98), pp. 243-273. (5)

MacDicken, K. 1997. Guidelines for Measuring Forest Carbon. Winrock International, Arlington VA.

Mclntosh, K., Krupnik, A. and Schenk, T. 1999. Utilizing Airborne Laser Altimetry for the improvement of Automatically Generated DEMs Over Urban Areas. International Archives of Photogrammetry and Remote Sensing, La Jolla, California, Vol. XXXII, W14, pp. 89-94. (7)

Optech, Incorporated. 2007.

http://www.optech.ca/pdf/Brochures/ALTM3100EAwspecsfnl.pdf accessed June 20, 2007.

Schultz, H., Slaymaker, D., Hanson, A., Riseman, E., Holmes, C., Powell, M., and Delaney, M. 1999. Cost-effective Determination of Biomass from Aerial Images, International Workshop on Integrated Spatial Data, Portland, Maine, June 14-15, 1999. (3)

Schultz, H., Slaymaker, D., Holmes, C., Stolle F., Hanson A. and Riseman, E. 1999. Integrating Small Format Aerial Photography, Videography, and a Laser Profiler for Environmental Monitoring, ISPRS WG III/5 Workshop on Integrated Sensor Calibration and Orientation, Portland, Maine, USA, June 16-17, 1999. (1)

Slaymaker, D., Schultz, H., Hanson, A., Riseman, E., Holmes, C., Powell, M., and Delaney, M. 1999. Calculating Forest Biomass With Small Format Aerial Photography, Videography And A Profiling Laser, ASPRS Proceedings of the 17th Biennial Workshop on Color Photography and Videography in Resource Assessment, Reno, Nevada, May 1999. (2)

Tiede, D., Hochleitner, G. and Blaschke, T. 2005. A Full GIS-based Workflow for Tree Identification and Tree Crown Delineation Using Laser Scanning. International Archives of Photogrammetry and Remote Sensing, Vienna, Austria, pp. 9-14. (4) 